\title{
Influence of spraying on the early hydration of accelerated cement
}

\section{pastes}

Renan P. Salvador ${ }^{\mathrm{a}, \mathrm{b}, 1}$, Sergio H. P. Cavalaro ${ }^{\mathrm{a}, 1}$, Miguel Cano ${ }^{\mathrm{c}}$, Antonio D. de Figueiredo $^{\mathrm{d}}$

a Department of Construction Engineering, BarcelonaTech, Polytechnic University of Catalonia, UPC, Jordi Girona 1-3, 08034, Barcelona, Spain.

${ }^{\mathrm{b}}$ CAPES Foundation, Ministry of Education of Brazil, Brasília - DF, 70040-020, Brazil.

c Industrias Químicas del Ebro, Poligono de Malpica, D 97, 50016, Zaragoza, Spain.

${ }^{d}$ Department of Civil Construction Engineering, Polytechnic School of University of São Paulo, USP, Professor Almeida Prado, Trav 2, 83, 05424-970, São Paulo, Brazil.

\begin{abstract}
In practice, most of the studies about the interaction between cement and accelerators is performed with hand-mixed pastes. However, in many applications mixing occurs through spraying, which may affect accelerators reactivity and the microstructure of the hardened paste. The objective of this study is to analyze how the mixing process influences the early hydration of accelerated cement pastes. Isothermal calorimetry, Xray diffraction, thermogravimetry and SEM imaging were performed on cement pastes produced by hand-mixing and by spraying, using equivalent doses of an alkali-free and an alkaline accelerator and two types of cement. Results showed a great influence of the spraying process on the reactivity of accelerators and on the morphology of the precipitated hydrates. Variations in hydration kinetics caused by the mixing method are explained and the results obtained might have a significant repercussion on how future research on the behavior of accelerated mixes will be performed.
\end{abstract}

Keywords: Cement Paste, Hydration, Microstructure, Accelerator, Mixing Process.

\footnotetext{
${ }^{1}$ Corresponding authors. Tel.: +34 934054247, Fax: +34 934011036.

E-mail addresses: renan.picolo@upc.edu (R Salvador); sergio.pialarissi@upc.edu (S Cavalaro).
} 


\section{Introduction}

Sprayed concrete differs from ordinary concrete due to the method of application and the use of set accelerators to promote rapid stiffening of the matrix right after mixing [1]. Accelerators are normally added to concrete at the nozzle, just before it is sprayed onto the substrate. In tunnel applications, these chemicals are necessary to provide high initial mechanical strength, so the concrete layer is able to provide support to the unstable ground. Depending on their chemical composition, different hydration mechanisms and mechanical strengths are observed in accelerated matrices [1,2].

In order to evaluate the compatibility and reactivity of accelerators with cement, the vast majority of studies deals with accelerated cement pastes produced by hand or mechanical mixing [2-7]. Martinez [3] showed that increasing mixing time and speed shortens setting times of accelerated cementitious mortars. Juilland [5,8] concluded that high mixing speeds have an acceleration effect on hydration kinetics in cement pastes with or without accelerator.

Despite the relevant conclusions derived from the studies from the literature, all of them are based on mixing processes that differ considerably from the one used in most applications. This is aggravated by the fact that nearly no study on the influence of the mixing process on the microstructure or hydration kinetics may be found. Lagerblad and Bryne [9] indicate that the paste preparation method might have significant influence on the microstructure. In addition to that, Lindlar et al [10] suggest that a more homogeneous dispersion of the accelerator is achieved through spraying and the hydrated products should present a more uniform distribution in the matrix when compared to a hand-mixed equivalent matrix. Juilland [5] describes that the massive ettringite formation during spraying fills up the matrix and less space remains for the silicate hydration to proceed. However, the repercussions in terms of the microstructure and in the chemical reactions involved are yet not clear.

The objective of this work is to investigate the influence of the production process on the hydration and the microstructure of cement pastes with accelerators. An experimental program was performed with two types of cement and two types of accelerator. For the study, three types of pastes were produced: reference hand-mixed pastes without accelerators, hand-mixed pastes with accelerators and sprayed pastes with accelerators. The composition and the production process of the hand-mixed pastes 
follow that normally found in the literature about the behavior of accelerators [2]. Conversely, the composition and the production process of sprayed pastes resemble those found in practice, being conditioned by the requirements of the equipment used.

A comparison between hand-mixed and sprayed accelerated pastes was performed. In order to characterize the kinetics and mechanisms of hydration, isothermal calorimetry, X-ray diffraction, thermogravimetry and SEM analysis were conducted. The study explains important differences in hydration behavior caused by the mixing process and highlights in which situations the characterization of matrices produced by spraying might be necessary.

\section{Experimental methodology}

The experimental program was performed at the Laboratory of Technology of Structures Luis Agulló at Universitat Politècnica de Catalunya (UPC) and at the Scientific and Technological Center from Universitat de Barcelona (CCIT-UB). In the following sections, materials, production processes and tests performed are described.

\subsection{Materials}

Two types of Portland cement (CEM I 52.5R and CEM II/A-L 42.5R) were used in this study. These cements were selected among the commonly used in sprayed concrete applications. CEM I is common in Spain and in countries from Asia and America, while CEM II/A-L is widely used in countries from northern Europe. Table 1 presents their mineralogical composition determined by XRD-Rietveld refinement, Table 2 shows their chemical composition determined by XRF spectrometry and Table 3 summarizes their chemical and physical properties.

Table 1 - Mineralogical composition of cements determined by XRD / Rietveld refinement.

\begin{tabular}{ccc}
\hline Compound & CEM I (\%) & CEM II/A-L (\%) \\
\hline $\mathrm{C}_{3} \mathrm{~S}$ & 58.3 & 51.7 \\
\hline $\mathrm{C}_{2} \mathrm{~S}$ & 11.2 & 6.7 \\
\hline $\mathrm{C}_{3} \mathrm{~A}_{\mathrm{c}}$ & 4.1 & 2.9 \\
\hline
\end{tabular}




\begin{tabular}{ccc}
\hline $\mathrm{C}_{3} \mathrm{~A}_{0}$ & 0.6 & 0.7 \\
\hline $\mathrm{C}_{4} \mathrm{AF}$ & 13.4 & 14.8 \\
\hline $\mathrm{CaO}$ & 1.1 & 1.2 \\
\hline $\mathrm{Ca}(\mathrm{OH})_{2}$ & 1.7 & 0.7 \\
\hline $\mathrm{CaCO}_{3}$ & 1.9 & 11.3 \\
\hline $\mathrm{CaSO}_{4} .2 \mathrm{H}_{2} \mathrm{O}$ & 2.1 & 0.7 \\
\hline $\mathrm{CaSO} \cdot 0_{4} .5 \mathrm{H}_{2} \mathrm{O}$ & 4.4 & 5.3 \\
\hline $\mathrm{K}_{2} \mathrm{SO}_{4}$ & - & 0.5 \\
\hline $\mathrm{K}_{2} \mathrm{Ca}_{\left(\mathrm{SO}_{4}\right)_{2} . \mathrm{H}_{2} \mathrm{O}}$ & 1.1 & - \\
\hline $\mathrm{MgO}$ & - & 0.6 \\
\hline $\mathrm{MgCO}_{3}$ & - & 3.1 \\
\hline $\mathrm{Total} \mathrm{sum}^{2}$ & 100.0 & 100.0 \\
\hline
\end{tabular}

Table 2 - Chemical composition of cements determined by XRF spectrometry.

\begin{tabular}{ccc}
\hline Compound & CEM I (\%) & CEM IIA-L (\%) \\
\hline $\mathrm{LOI}$ & 2.88 & 6.42 \\
\hline $\mathrm{CaO}$ & 62.62 & 62.48 \\
\hline $\mathrm{SiO}_{2}$ & 19.89 & 17.61 \\
\hline $\mathrm{Al}_{2} \mathrm{O}_{3}$ & 4.74 & 4.04 \\
\hline $\mathrm{Fe}_{2} \mathrm{O}_{3}$ & 3.26 & 3.53 \\
\hline $\mathrm{SO}_{3}$ & 3.53 & 3.21 \\
\hline $\mathrm{MgO}$ & 1.95 & 1.69 \\
\hline $\mathrm{K}_{2} \mathrm{O}$ & $0.99(0.98)^{\mathrm{a}}$ & $0.83(0.62)^{\mathrm{a}}$ \\
\hline $\mathrm{Na}_{2} \mathrm{O}$ & $0.13(0.011)^{\mathrm{a}}$ & $0.13(0.035)^{\mathrm{a}}$ \\
\hline Minor components & 0.11 & 0.09 \\
\hline Total sum & 100.0 & 100.0 \\
\hline
\end{tabular}

\footnotetext{
${ }^{a} \mathrm{~K}_{2} \mathrm{O}$ and $\mathrm{Na}_{2} \mathrm{O}$ readily soluble, determined by ion chromatography from a solution extracted from a
} cement suspension with w/c equal to $9[11,12]$.

Table 3 - Chemical and physical properties of cements.

\begin{tabular}{ccc}
\hline Property & CEM I & CEM II/A-L \\
\hline Total heat of hydration $^{\mathrm{a}}(\mathrm{J} / \mathrm{g})$ & 433.0 & 381.0 \\
\hline $\mathrm{C}_{3} \mathrm{~A} / \mathrm{SO}_{3}$ molar ratio & 0.39 & 0.33 \\
\hline
\end{tabular}




\begin{tabular}{ccc}
\hline Insoluble residue $(\%)$ & 2.74 & 2.90 \\
\hline Specific surface BET $\left(\mathrm{m}^{2} / \mathrm{g}\right)$ & 2.96 & 1.88 \\
\hline $\mathrm{d}_{50}(\mu \mathrm{m})$ & 11.4 & 15.7 \\
\hline
\end{tabular}

a The total heat of hydration was estimated from the mineralogical composition of the cement, determined by XRD, as the relative sum of the heats of hydration of the individual phases $\left(\mathrm{C}_{3} \mathrm{~S}: 510 \mathrm{~J} / \mathrm{g} ; \mathrm{C}_{2} \mathrm{~S}: 260 \mathrm{~J} / \mathrm{g}\right.$; $\mathrm{C}_{3} \mathrm{~A}: 1100 \mathrm{~J} / \mathrm{g} ; \mathrm{C}_{4} \mathrm{AF}: 410 \mathrm{~J} / \mathrm{g}[13]$.

Distilled water and a superplasticizer based on a polycarboxylate solution (34\% of solid content) were used to prepare all pastes. One alkali-free accelerator composed by an aluminum hydroxysulfate solution stabilized by an organic acid and one alkaline accelerator based on sodium aluminate were used to cover the types commonly found in practice. Composition and pH of accelerators are presented in Table 4.

Table 4 - Compositions and $\mathrm{pH}$ of accelerators.

\begin{tabular}{ccc}
\hline Characteristic & Alkali-free & Alkaline \\
\hline Solid content $(\%)$ & 47.6 & 43.0 \\
\hline $\mathrm{Al}_{2} \mathrm{O}_{3}$ content $(\%)$ & 13.5 & 24.0 \\
\hline $\mathrm{SO}_{4}{ }^{2-} \operatorname{content}(\%)$ & 21.0 & - \\
\hline $\mathrm{Na}_{2} \mathrm{O}$ content $(\%)$ & - & 19.0 \\
\hline $\mathrm{pH}$ at $20^{\circ} \mathrm{C}$ & 3.0 & $12.0^{\mathrm{a}}$ \\
\hline
\end{tabular}

${ }^{a}$ Solution at $1.0 \%$.

\subsection{Compositions and preparation of cement pastes}

The composition and preparation procedure of the mixes studied are presented in sections 2.2.1 and 2.2.2 depending on how accelerators are mixed with the paste. Cement pastes were prepared under controlled climatic conditions, at $20{ }^{\circ} \mathrm{C}$ and $50 \%$ relative humidity.

The nomenclature adopted to identify each composition follows the pattern 'cement type'_accelerator type'_mixing process'_'w/c ratio'. Alkali-free and alkaline accelerators are abbreviated as AKF and ALK, respectively. Regarding the mixing process, HM corresponds to hand-mixed and SP to sprayed pastes. Reference pastes do 
not contain accelerators and are identified by 'cement type' $R E F_{-}$'mixing process' ${ }_{-} w / c$ ratio'.

\subsubsection{Hand-mixed pastes}

Reference pastes are composed by cement, a water/cement ratio equal to 0.45 and $1.0 \%$ of superplasticizer by cement weight $(\% \mathrm{bcw})$. In accelerated pastes, the alkali-free accelerator was used at $7.0 \% \mathrm{bcw}$, whereas the alkaline accelerator was added at the dosage of $3.0 \% \mathrm{bcw}$. Those contents were determined according to the procedure described in [1] to assure equivalent mechanical performance in pastes and fall within the dosages usually applied in tunnels executed with sprayed concrete.

The composition of each paste in terms of ions and compounds present is described in Table 5. An information of interest is the final $\mathrm{C}_{3} \mathrm{~A} / \mathrm{SO}_{3}$ ratio after accelerator addition. As the alkaline accelerator does not contain any sulfates in its composition, $\left[\mathrm{Al}(\mathrm{OH})_{4}\right]^{-}$consumes approximately $48 \%$ of the sulfate present in cement, resulting in a final $\mathrm{C}_{3} \mathrm{~A} / \mathrm{SO}_{3}$ ratio two times higher than the initial value from cement. This effect is less pronounced when the alkali-free accelerator is used, since this admixture contains sulfate ions in its formulation.

Table 5 - Ionic composition in accelerated cement pastes.

\begin{tabular}{|c|c|c|c|c|}
\hline n (mmol/g cement) & CEM I_AKF & CEM I_ALK & CEM II_AKF & CEM II_ALK \\
\hline Total $\mathrm{SO}_{4}{ }^{2-}$ in cement ${ }^{\mathrm{a}}$ & 0.441 & 0.441 & 0.401 & 0.401 \\
\hline $\mathrm{Al}$ in accelerator ${ }^{\mathrm{b}}$ & 0.185 & 0.141 & 0.185 & 0.141 \\
\hline $\mathrm{SO}_{4}{ }^{2-}$ in accelerator & 0.153 & - & 0.153 & - \\
\hline $\mathrm{H}^{+}$in accelerator & 0.163 & - & 0.163 & - \\
\hline $\mathrm{Na}^{+}$in accelerator & - & 0.184 & - & 0.184 \\
\hline Ettringite formed & 0.093 & 0.071 & 0.093 & 0.071 \\
\hline $\begin{array}{c}\mathrm{SO}_{4}^{2-} \text { consumed in ettringite } \\
\text { formation }\end{array}$ & 0.278 & 0.212 & 0.278 & 0.212 \\
\hline $\mathrm{SO}_{4}^{2-}$ left & 0.316 & 0.229 & 0.276 & 0.189 \\
\hline Final $\mathrm{C}_{3} \mathrm{~A} / \mathrm{SO}_{3}$ molar ratio ${ }^{\mathrm{c}}$ & 0.55 & 0.76 & 0.48 & 0.70 \\
\hline
\end{tabular}

${ }^{a}$ Determined by ionic chromatography with a solution obtained from the dissolution of $1.00 \mathrm{~g}$ of cement in $10.0 \mathrm{~mL}$ of concentrated nitric acid, according to [14].

${ }^{\mathrm{b}}$ Aluminum corresponds to $\mathrm{Al}^{3+}$ and $\left[\mathrm{Al}(\mathrm{OH})_{4}\right]^{-}$in alkali-free and alkaline accelerators, respectively. 
${ }^{c}$ The final $\mathrm{C}_{3} \mathrm{~A} / \mathrm{SO}_{3}$ ratio was calculated considering the sulfate amount remaining after accelerator reaction and the initial $\mathrm{C}_{3} \mathrm{~A}$ content of cements.

References pastes were prepared by pre-mixing water and superplasticizer and homogenizing the resulting solution with cement by means of a vortex external mixer during 60 seconds. In hand-mixed accelerated pastes, accelerators were added to the pastes 1 hour after cement and water had been mixed. The resulting mix was vigorously homogenized for 15 seconds with a spatula. During the period between the mixing of cement and water and accelerator addition, the paste was kept inside a calorimeter at 20 ${ }^{\circ} \mathrm{C}$ in order to avoid the influence of variations in temperature.

This procedure intends to reproduce the condition usually found in practice, since the introduction of the accelerator only occurs almost one hour after the mixing of the other components. Moreover, this also allows a clearer evaluation of the heat flow attributed to the addition of accelerator, which otherwise would overlap with the initial heat release observed in the mixing of cement and water.

\subsubsection{Sprayed pastes}

Sprayed pastes contained the same superplasticizer and accelerators dosages as hand-mixed pastes, presenting the composition shown in Table 5. However, the use of a w/c ratio equal to 0.45 was not feasible given the typical requirements of the spraying equipment. In fact, the use of such a high w/c ratio compromises the adequate setting of the paste right after accelerator addition and its stable adhesion to the surface of the substrate. For this reason, pastes destined to spraying were produced using a w/c ratio equal to $0.32^{2}$.

Batches containing 30 kilograms of paste were necessary to comply with the requirements of the spraying equipment (described in section 2.3) and to assure a homogeneous flow of paste through the pumping system. For this reason, cement pastes were prepared in a planetary mixer type 65/2 K-3, using $65 \mathrm{~L}$ containers. Paddle rotation and planetary speeds were 150 and $40 \mathrm{rpm}$, respectively.

\footnotetext{
${ }^{2}$ For comparison purposes, accelerated hand-mixed pastes were also produced with a w/c ratio of 0.32 and were analyzed by isothermal calorimetry. Results are presented in appendix 1.
} 
Cement and water were mixed for 240 seconds, followed by superplasticizer addition and more 240 seconds of mixing. Accelerator was added to the paste by spraying 1 hour after cement and water had been homogenized. The paste was kept in a climatic chamber at $20{ }^{\circ} \mathrm{C}$ before accelerator incorporation, in order to follow the same procedures as in hand-mixed pastes.

\subsection{Small-scale spraying equipment}

The system employed to produce sprayed pastes corresponds to a small-scale version of a concrete spraying equipment used in previous research [1] and is presented in Figure 1. A helical screw pump type UP-Pictor was used. This type of pump is adequate for fluids like cement pastes, in contrast with piston pumps that are indicated to handle fluids with coarser particles [15]. It also assures a more constant flow of material, eliminating the pulsation effect. It is operated with the pressure of 6 bar, using a $3 \mathrm{HP}$ air compressor. The hose for transporting the paste has a diameter of $40 \mathrm{~mm}$ and a length of $4 \mathrm{~m}$.

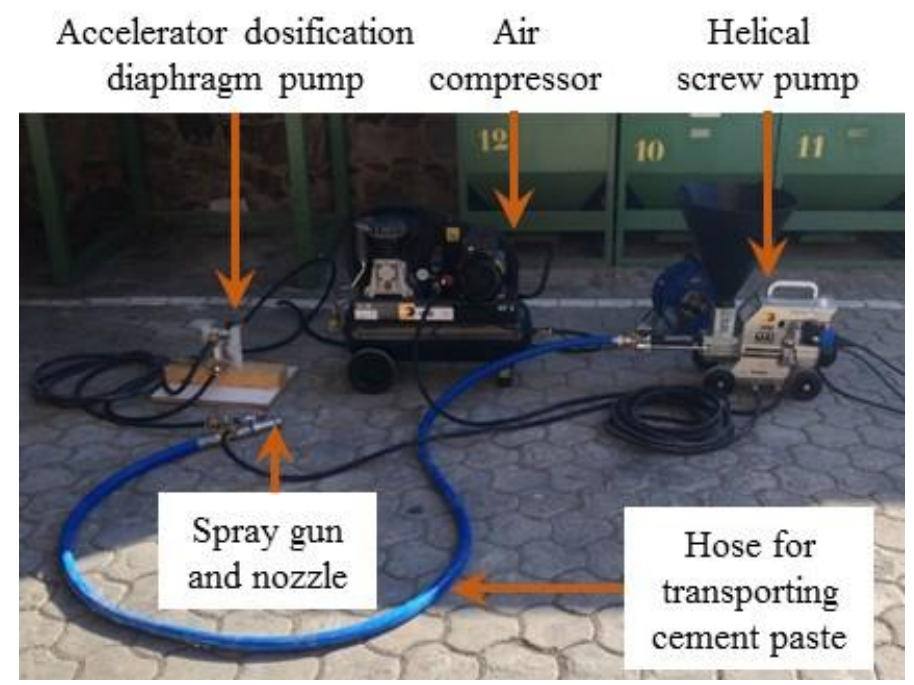

Figure 1 - Components of the spraying equipment for cement pastes.

A spray gun is connected at the end of the hose and its details are presented in Figure 2. It contains three different inlets for the ingress of cement paste, accelerator and compressed air (Figure 2.a). A nozzle developed specifically for this study is connected at the exit of the gun (Figure 2.b). It has a frustum shape with base diameter, top diameter and height equal to 14.0, 6.0 and $10.0 \mathrm{~mm}$, respectively. At the top part, an 
extension cylinder measuring $30.0 \mathrm{~mm}$ in length and $6.0 \mathrm{~mm}$ in inner diameter was installed in order to obtain a better homogenization of the sprayed mix. At its base, six 2 mm-holes for the inlet of accelerator and compressed air are found (see Figure 2.c).

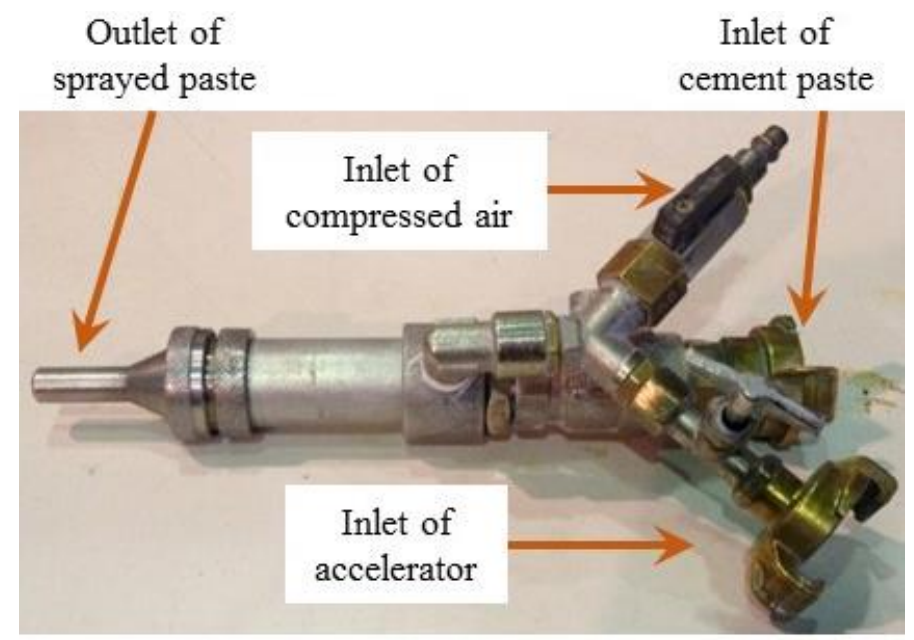

(a)

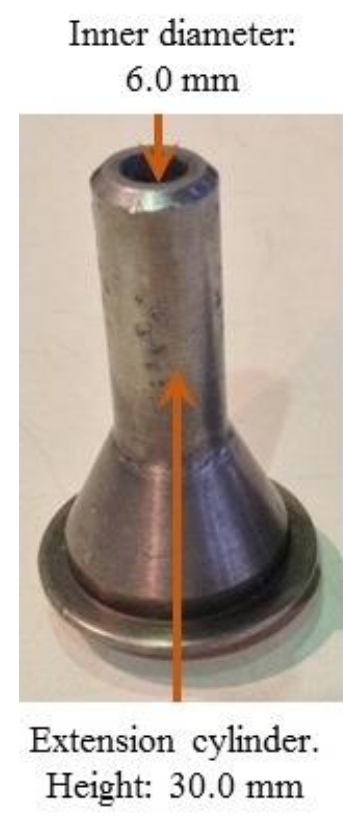

(b)

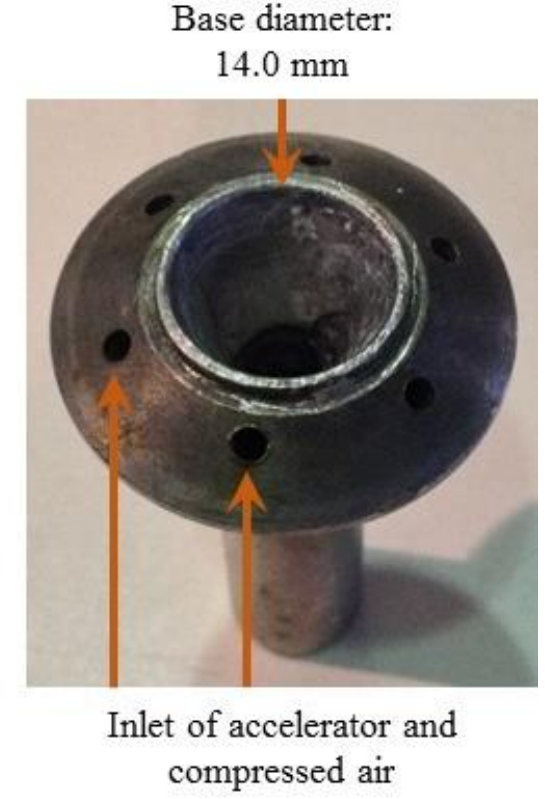

(c)

Figure 2 - Spray gun (a), nozzle for cement pastes (b) and base view of the nozzle, showing the holes for the inlet of accelerator and compressed air (c).

Accelerators are dosed by an air-operated diaphragm pump type P.025. This type of pump presented a homogeneous suction for all the accelerators, since their viscosity varied according to their chemical composition. The flow of accelerators depended on their type and dosage and was calculated based on the optimal flow of cement paste (4.9 liters of per minute). 


\subsection{Test methods}

Table 6 presents the tests executed with accelerated pastes. Their descriptions are presented subsequently. Samples were destined to the tests right after accelerator homogenization. Accelerator addition was considered as the beginning of all the tests.

Table 6 - Tests executed with accelerated pastes.

\begin{tabular}{ccccc}
\hline Test & Cement type & $\begin{array}{c}\text { Preparation } \\
\text { procedure }\end{array}$ & Sample state & Age / period of time \\
\hline $\begin{array}{c}\text { Isothermal } \\
\text { calorimetry }\end{array}$ & I and II/A-L & HM and SP & Fresh & $0-24 \mathrm{~h}$ \\
\hline $\begin{array}{c}\text { Evolution of } \\
\text { temperature }\end{array}$ & I and II/A-L & HM and SP & Fresh & $1-1.5 \mathrm{~h}$ \\
\hline In situ XRD & I and II/A-L & HM & Fresh & $0-24 \mathrm{~h}$ \\
\hline Powder XRD & I and II/A-L & SP & Frozen and ground & 15 min, 1, 3, 12 and $24 \mathrm{~h}$ \\
\hline TGA & I & HM and SP & Freeze-dried and ground & 15 min, 3, 12 and $48 \mathrm{~h}$ \\
\hline SEM & I & HM and SP & Freeze-dried & $15 \mathrm{~min}, 3$ and $12 \mathrm{~h}$ \\
\hline
\end{tabular}

Isothermal calorimetry was performed at $20{ }^{\circ} \mathrm{C}$ during 24 hours with 15.0 grams of cement paste, using an I-cal 4000 isothermal calorimeter.

Evolution of temperature was measured in a semiadiabatic calorimeter with 300 grams of cement paste, using thermocouples type $\mathrm{K}$. This test started right after accelerator addition and was performed for 30 minutes.

In situ X-ray diffraction was conducted in a PANalytical X'Pert PRO MPD $\theta / \theta$ powder diffractometer in reflection Bragg-Brentano geometry equipped with a PIXcel detector (active length of $3.347^{\circ}$ ) and a fixed divergence slit of $0.5^{\circ}$. It operates with Ni-filtered $\mathrm{CuK} \alpha$ radiation $(\lambda=1.5418 \AA$ ) at $45 \mathrm{kV}$ and $40 \mathrm{~mA}$. Sample holders were cylindrical, with a diameter of $32 \mathrm{~mm}$ and a depth of $3 \mathrm{~mm}$. They contained approximately 3.7 grams of paste and were spun at 2 revolutions per second. Pastes were covered with a Kapton® polyimide film (thickness of $7.5 \mu \mathrm{m}$ ) to avoid water evaporation and contact with atmospheric $\mathrm{CO}_{2}$.

Diffraction patterns were recorded from $5^{\circ} 2 \theta$ to $55^{\circ} 2 \theta$, using a step width of $0.026^{\circ} 2 \theta$ and 20.9 seconds per step. Under these data acquisition conditions, a powder diagram is recorded in approximately 200 seconds. The first diagram was obtained 5 minutes after accelerator addition and, then, every 15 minutes during 24 hours. They 
were analyzed semi-quantitatively by Rietveld refinement using the software X'Pert HighScore Plus with the structure models shown in Table 7.

Table 7 - References of the different phase structures used for Rietveld refinement.

\begin{tabular}{|c|c|c|c|c|c|c|}
\hline Phase & Formula & $\begin{array}{l}\text { Crystal } \\
\text { system }\end{array}$ & $\begin{array}{c}\text { PDF } \\
\text { number }\end{array}$ & $\begin{array}{l}\text { ICSD } \\
\text { code }\end{array}$ & Reference & Year \\
\hline Alite & $\mathrm{Ca}_{3} \mathrm{SiO}_{5}$ & Monoclinic & $01-070-8632$ & 94742 & {$[16]$} & 2002 \\
\hline Belite & $\mathrm{Ca}_{2} \mathrm{SiO}_{4}$ & Monoclinic $(\beta)$ & 01-083-0460 & 79550 & [17] & 1994 \\
\hline Calcium aluminate & $\mathrm{Ca}_{3} \mathrm{Al}_{2} \mathrm{O}_{6}$ & Cubic & 00-038-1429 & 1841 & {$[18]$} & 1975 \\
\hline Ferrite & $\mathrm{Ca}_{2} \mathrm{AlFeO}_{5}$ & Orthorhombic & $01-071-0667$ & 9197 & [19] & 1971 \\
\hline Gypsum & $\mathrm{CaSO}_{4} \cdot 2 \mathrm{H}_{2} \mathrm{O}$ & Monoclinic & 00-033-0311 & 151692 & {$[20]$} & 2004 \\
\hline Calcite & $\mathrm{CaCO}_{3}$ & Rhombohedral & 01-083-0577 & 79673 & {$[21]$} & 1989 \\
\hline Portlandite & $\mathrm{Ca}(\mathrm{OH})_{2}$ & Rhombohedral & $01-072-0156$ & 15741 & {$[22]$} & 1961 \\
\hline Ettringite & $\begin{array}{l}\mathrm{Ca}_{6} \mathrm{Al}_{2}\left(\mathrm{SO}_{4}\right)_{3} . \\
(\mathrm{OH})_{12 .} 26 \mathrm{H}_{2} \mathrm{O}\end{array}$ & Hexagonal & $00-041-1451$ & 155395 & [23] & 2006 \\
\hline Monosulfoaluminate & $\begin{array}{c}3 \mathrm{CaO} \mathrm{Al}_{2} \mathrm{O}_{3} . \\
\mathrm{CaSO}_{4} \cdot 12 \mathrm{H}_{2} \mathrm{O}\end{array}$ & Rhombohedral & - & 24461 & [24] & 1968 \\
\hline Hemicarboaluminate & $\begin{array}{c}\mathrm{Ca}_{4} \mathrm{Al}_{2}(\mathrm{OH})_{12 .} . \\
\mathrm{OH} .0 .5 \mathrm{CO}_{3} .4 \mathrm{H}_{2} \mathrm{O}\end{array}$ & Rhombohedral & 00-041-0221 & 263124 & {$[25]$} & 2012 \\
\hline Monocarboaluminate & $\begin{array}{c}\mathrm{Ca}_{4} \mathrm{Al}_{2}(\mathrm{OH})_{12} \\
\mathrm{CO}_{3} .5 \mathrm{H}_{2} \mathrm{O}\end{array}$ & Triclinic & 01-087-0493 & 59327 & {$[26]$} & 1998 \\
\hline
\end{tabular}

In situ XRD was not performed with sprayed pastes due to the logistics involved in the spraying process. Instead, sprayed pastes were frozen in liquid nitrogen to stop hydration at 15 minutes, 1, 3, 12 and 24 hours after accelerator addition. Then, they were crushed and ground to a maximum size of $63 \mu \mathrm{m}$ still in frozen state to avoid the influence of further hydration in phase composition. Pastes were not lyophilized because the stability and crystallinity of ettringite and monosulfoaluminate could be compromised, as indicated by [27]. A powder diagram was recorded right after grinding using the same test configuration as in situ XRD.

Thermal analysis was performed from 30 to $1000{ }^{\circ} \mathrm{C}$ at a heating rate of 10 ${ }^{\circ} \mathrm{C} / \mathrm{min}$ with $\mathrm{N}_{2}$ flow of $50 \mathrm{~mL} / \mathrm{min}$ using a SDT Q-600 thermobalance. Cement pastes were frozen in liquid nitrogen at 15 minutes, 3, 12 and 48 hours after accelerator addition and dried in vacuum during 24 hours. Then, they were crushed and ground to a maximum diameter of $63 \mu \mathrm{m}$ using an agate mortar. In each analysis, approximately 25 milligrams of paste were tested in $90 \mu \mathrm{L}$ alumina crucibles.

Portlandite was quantified by its dehydration, calculating the mass loss in the temperature range from 350 to $500{ }^{\circ} \mathrm{C}$. Chemically bound water was calculated from 40 
to $1000{ }^{\circ} \mathrm{C}$, correcting the value obtained by the mass loss corresponding to the decarbonation of anhydrous cement, according to [28]. This temperature range was adopted because only the non-evaporable water remains in freeze-dried pastes [27].

Scanning electron microscopy was conducted in a JEOL JSM 7100F microscope at the voltage of $20 \mathrm{kV}$. Cement pastes were frozen in liquid nitrogen 15 minutes, 3 and 12 hours after accelerator homogenization, dried in vacuum during 24 hours and coated with carbon. Morphology of the precipitated hydrates was analyzed by secondary electron imaging of fracture surfaces and their chemical composition was assessed by energy dispersive X-ray analysis.

\section{Results and discussion}

Results obtained with all the test methods are presented from sections 3.1 to 3.5. Appendix 1 shows heat of hydration curves obtained with hand-mixed pastes prepared with different w/c ratios.

\subsection{Isothermal calorimetry}

Heat of hydration curves of hand-mixed and sprayed pastes are shown in Figure 3. Results obtained with CEM I pastes are presented on the left, whereas results from CEM II/A-L pastes are on the right. Figure 3.a and 3.b represent the curve from 0 to 24 hours. Figure 3.c and 3.d show a zoom of the heat of hydration curve from 1.0 to 1.5 hours, which corresponds to heat flow generated by accelerator addition (named accelerator peak hereinafter). 


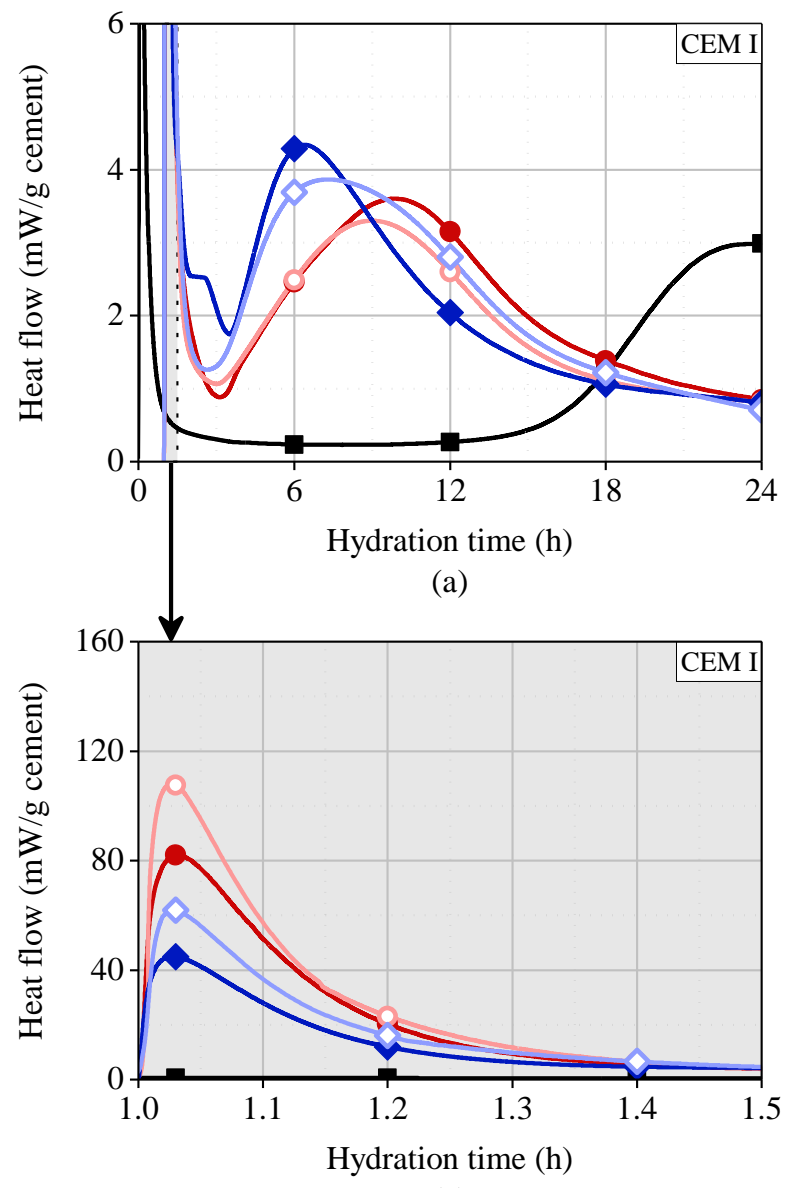

(c)

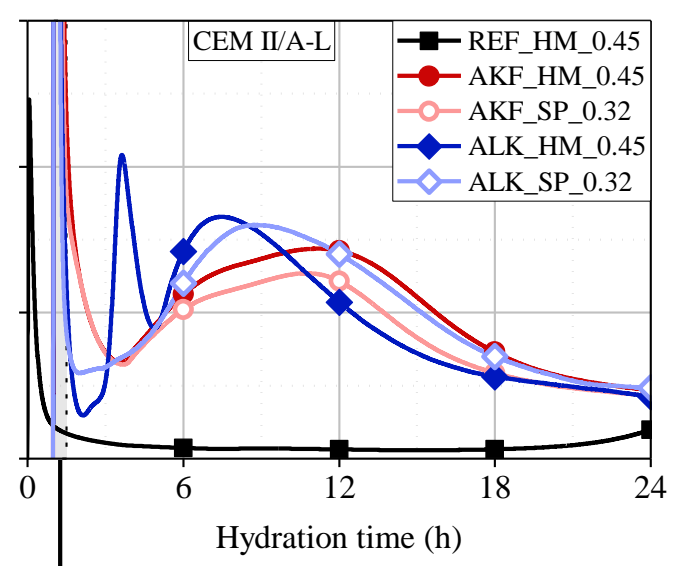

(b)

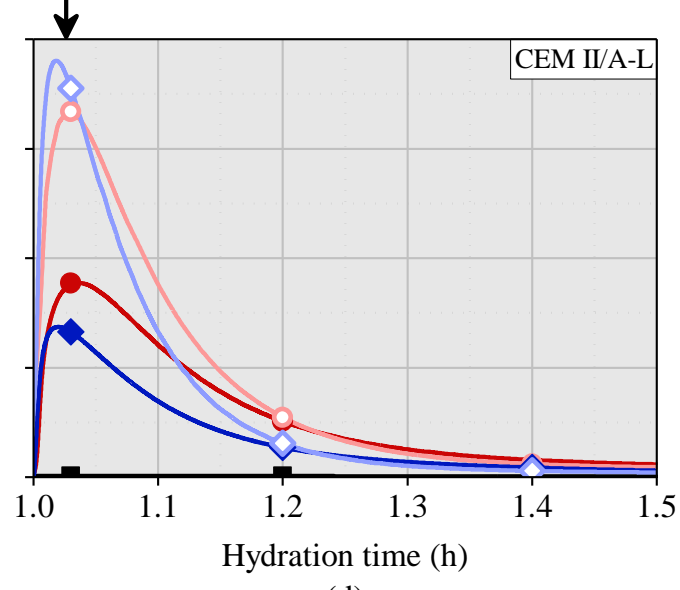

(d)

Figure 3 - Heat flow curves obtained from 0 to $24 \mathrm{~h}$ (a and $\mathrm{b}$ ) and from 1.0 to $1.5 \mathrm{~h}$ (c and d).

The characteristic points of the heat flow curves are summarized in Table 8. The curves of the reference paste were not considered in this analysis due to the significant retardation caused by the superplasticizer. The accelerator peak occurs as a consequence of ettringite formation. After that, the main hydration peak is observed, where alite consumption and the precipitation of portlandite and C-S-H take place. As CEM I contains $58.3 \%$ of alite and $4.7 \%$ of $\mathrm{C}_{3} \mathrm{~A}$, while these compounds are present in $51.7 \%$ and $3.6 \%$ in CEM II/A-L (Table 1), shorter induction periods and higher intensities in the main hydration peak are observed in CEM I pastes. These parameters are also influenced by cement fineness (CEM I is finer than CEM II/A-L, Table 3).

Table 8 - Analysis of the heat flow curves obtained with the accelerated pastes.

\begin{tabular}{ccccccccc}
\hline Variable & $\begin{array}{c}\text { CEM I_ } \\
\text { AKF_HM } \\
\mathbf{0 . 4 5}\end{array}$ & $\begin{array}{c}\text { CEM I_- } \\
\text { ALK_HM } \\
\mathbf{0 . 4 5}\end{array}$ & $\begin{array}{c}\text { CEM II_ } \\
\text { AKF_HM } \\
\mathbf{0 . 4 5}\end{array}$ & $\begin{array}{c}\text { CEM II_- } \\
\text { ALK_HM } \\
\mathbf{0 . 4 5}\end{array}$ & $\begin{array}{c}\text { CEM I_ } \\
\text { AKF_SP } \\
\mathbf{0 . 3 2}\end{array}$ & $\begin{array}{c}\text { CEM I_ } \\
\text { ALK_SP } \\
\mathbf{0 . 3 2}\end{array}$ & $\begin{array}{c}\text { CEM II_ } \\
\text { AKF_SP } \\
\mathbf{0 . 3 2}\end{array}$ & $\begin{array}{c}\text { CEM II_- } \\
\text { ALK_SP } \\
\mathbf{0 . 3 2}\end{array}$ \\
\hline $\begin{array}{c}\text { Slope - accelerator peak } \\
\text { (mW/g.h) }\end{array}$ & 2231 & 1187 & 1554 & 2207 & 4644 & 2434 & 3465 & 8685 \\
\hline
\end{tabular}




\begin{tabular}{|c|c|c|c|c|c|c|c|c|}
\hline $\begin{array}{c}\text { Energy released - } \\
\text { accelerator peak }(\mathrm{J} / \mathrm{g})\end{array}$ & 32.79 & 14.25 & 30.38 & 14.50 & 53.07 & 35.40 & 60.83 & 51.60 \\
\hline $\begin{array}{l}\text { Maximum heat flow - } \\
\text { accelerator peak }(\mathrm{mW} / \mathrm{g})\end{array}$ & 82.0 & 45.0 & 71.0 & 54.9 & 108.3 & 62.1 & 133.7 & 152.4 \\
\hline Induction period $(\mathrm{min})$ & 108.6 & 130.2 & 130.5 & 144.4 & 105.6 & 99.4 & 128.6 & 143.0 \\
\hline $\begin{array}{c}\text { Slope acceleration - main } \\
\text { peak (mW/g.h) }\end{array}$ & 0.58 & 1.34 & 0.40 & 1.20 & 0.52 & 1.02 & 0.36 & 0.57 \\
\hline $\begin{array}{c}\text { Energy released - main } \\
\text { peak }^{\mathrm{b}}(\mathrm{J} / \mathrm{g})\end{array}$ & 147.8 & 133.3 & 140.0 & 135.3 & 125.0 & 152.7 & 111.2 & 141.9 \\
\hline $\begin{array}{l}\text { Maximum heat flow - } \\
\text { main peak }(\mathrm{mW} / \mathrm{g})\end{array}$ & 3.60 & 4.34 & 2.88 & 3.31 & 3.30 & 3.87 & 2.54 & 3.20 \\
\hline
\end{tabular}

${ }^{a}$ The energy corresponding to the accelerator peak in hand-mixed pastes was corrected using the variation of heat generated by the removal of the sample from the calorimeter for the addition of the accelerator. The area under the curve was calculated from 1.0 to $1.5 \mathrm{~h}$.

$\mathrm{b}$ The area under the main hydration peak was calculated from the end of the induction period until the time when the heat flow reached $1.0 \mathrm{~mW} / \mathrm{g}$ of cement in the deceleration period.

Results indicate that the rate of accelerator reaction (considered as the slope of the ascending part of the accelerator peak) is more than two times higher in sprayed pastes in comparison with hand-mixed pastes. As this rate depends on the mixing procedure, it can be assumed that it is transport controlled. In other words, the homogenization of the accelerator ions into the matrix is the limiting process of the reaction [5]. The stronger shearing conditions achieved through spraying turn the paste and the accelerator into small particles, as aerosols, and the reaction takes place faster due to a better homogenization.

A similar outcome is observed if the energy released and the maximum heat flow of the accelerator peak are analyzed. Again, sprayed pastes reach values considerably higher than the equivalent hand-mixed ones. The biggest difference is verified in pastes with CEM II/A-L, due to the presence of limestone filler. Calcium carbonate from the filler may react with aluminate ions from both accelerators and may also be partially dissolved by the $\mathrm{H}^{+}$ions contained in the alkali-free accelerator [29]. Both processes contribute to increase the heat generated in the accelerator peak.

A small influence of the mixing process was observed on the onset of the main hydration peak. Induction periods are slightly shorter in sprayed pastes. The more effective accelerator dispersion achieved in sprayed pastes leads to an enhancement in nucleation and growth of hydrates, due to a faster consumption of calcium and sulfate ions from the liquid phase. This favors alite and gypsum dissolution in order to balance calcium concentration in the chemical equilibria. Then, silicate ion concentration also increases, favoring the nucleation process and producing a small shortening of the 
induction periods. In hand-mixed pastes, ion diffusion in the liquid phase is not as efficient, leading to a small delay in balancing the chemical equilibria disturbed by the accelerators and postponing the onset of the acceleration period.

The rate of heat flow during the acceleration period, the energy released and the maximum heat flow obtained in the main hydration peak are also influenced by the mixing process (Table 8). Hand-mixed and sprayed pastes containing the alkali-free accelerator present the same general mechanisms of hydration for both cements. However, the rate of hydration in sprayed pastes is lower, consequently decreasing the extent of alite hydration, as observed by the smaller energy released and maximum heat flow obtained in the main peak.

The same behavior is observed in hand-mixed pastes produced with the alkaline accelerator. Taking into account that the aluminate accelerator consumes approximately $50 \%$ of the sulfate available in the paste and part of the sulfates left are adsorbed onto $\mathrm{C}-\mathrm{S}-\mathrm{H}$ surface, further $\mathrm{C}_{3} \mathrm{~A}$ hydration proceeds as in undersulfated systems (higher $\mathrm{C}_{3} \mathrm{~A} / \mathrm{SO}_{3}$ ratio in Table 5). In heat flow curves, a separation of the main hydration peak in two thermal events occurs. It can be observed by a bump around 2.5 hours in the paste CEM I_ALK_HM_0.45 in Figure 3.a and by the first sharp peak occurring around 3.6 hours in the paste CEM II_ALK_HM_0.45 in Figure 3.b, due to the formation of AFm phases. Monosulfoaluminate is preferentially formed when limestone is not present [30,31], while hemicarboaluminate or monocarboaluminate might be formed with additions of filler higher than $4 \%$ by mass [11].

However, in sprayed pastes with the alkaline accelerator (CEM I_ALK_SP_0.32 and CEM II_ALK_SP_0.32), this dissociated peak is not observed. A possible explanation to such difference is that the AFm formation might be advanced in time and take place during the accelerator peak due to the more efficient dispersion achieved with the spraying process. Consequently, the exothermal heat signals generated in ettringite and AFm formation are overlapped and cannot be distinguished. The accelerated formation of AFm phases also contributes to decrease the extent of alite hydration, lowering the intensity in the main hydration peak in sprayed pastes. The energy released in the main hydration peak is higher in sprayed pastes because the high shearing condition and high temperature reached during spraying accelerate $\mathrm{C}_{3} \mathrm{~A}$ reactions, which occur concurrently with alite hydration (see sections 3.2 and 3.3).

This early formation of AFm phases is more pronounced in CEM II_ALK_SP_0.32 paste due to the presence of limestone filler. In this paste, the 
intensity reached in the accelerator peak is the highest. The spraying process might favor the dissolution of calcium carbonate and its contact with aluminate ions, contributing to the formation of carbonated AFm phases, like hemi or monocarboaluminate. The formation of these phases indirectly stabilizes ettringite [11]. Since ettringite is the main product that provides initial mechanical strength when such accelerators are used, limestone filler may improve their reactivity in sprayed concrete applications [1].

The rate of reaction during the main hydration peak can also be observed in the energy release curves from Figure 4. The curves corresponding to the sprayed pastes with the alkali-free accelerator present a lower reaction rate (constant decrease in slope) from 12 hours on. As the accelerator reaction occurs faster in sprayed pastes, aluminate hydrates fill up the pores more quickly, inhibiting the precipitation of silicate hydrates due to a lack of space [5]. This leads to lower degrees of hydration in sprayed pastes until 24 hours. In other words, sprayed pastes tend to present higher reaction rates when the accelerator is added and lower hydration rates in the following hours.

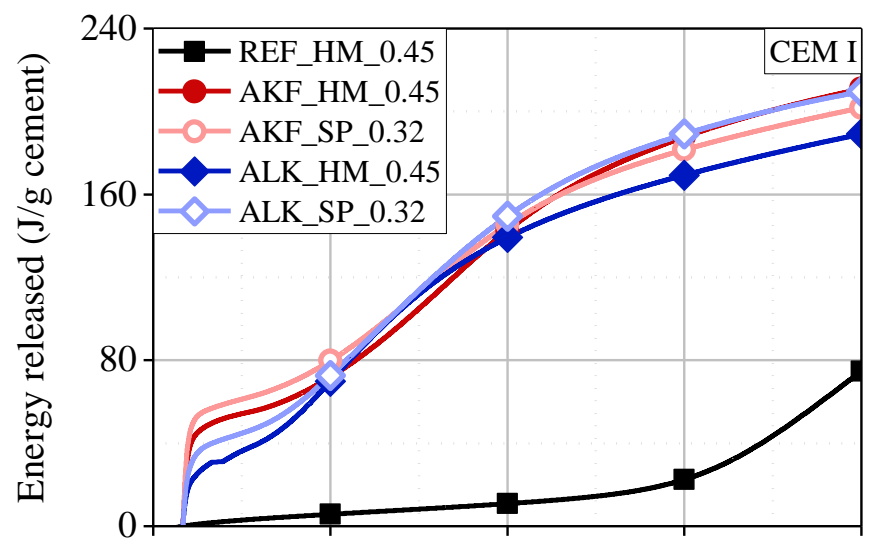

(a)

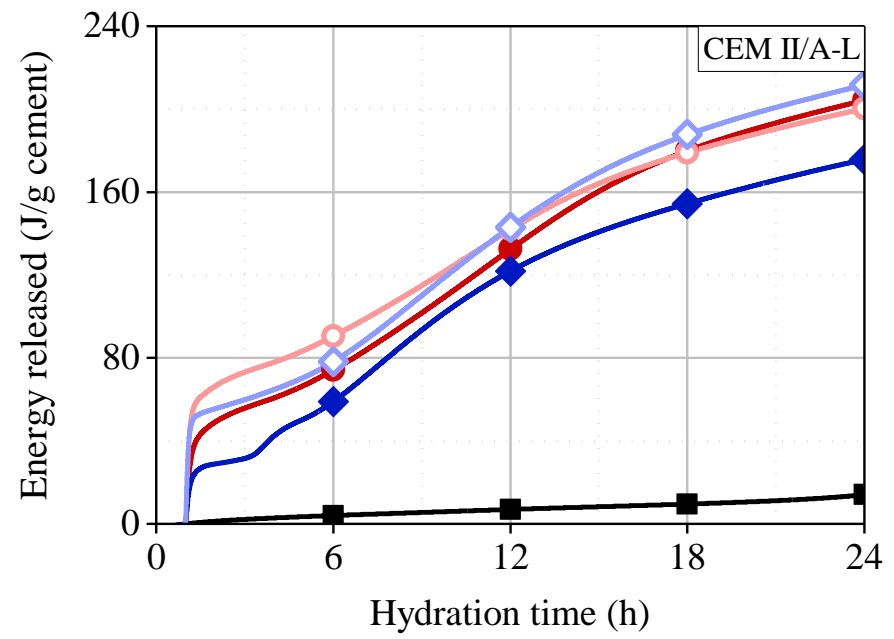

(b) 
The same behavior is observed in the pastes with the alkaline accelerator. In sprayed pastes, lower rates of hydration and lower maximum heat flows are observed. The accelerated $\mathrm{C}_{3} \mathrm{~A}$ reaction causes a delay in alite hydration, broadening the main hydration peak and lowering its intensity. In this case, alite solubility might be the limiting step of the hydration process, as also observed in [2].

The spraying process mainly influences systems with higher $\mathrm{C}_{3} \mathrm{~A} / \mathrm{SO}_{3}$ ratios, such as pastes with alkaline accelerators. The accelerated formation of AFm phases influences alite hydration. Since alkali-free accelerators present a minor change in the sulfate balance in the pastes, the effect of spraying on cement hydration with this type of accelerator is not as significant as in alkaline accelerated pastes.

\subsection{Evolution of temperature}

Evolution of temperature in hand-mixed and sprayed pastes is shown in Figure 5. The temperature of the matrix during the accelerator peak in sprayed pastes is always higher than in hand-mixed pastes. Faster hydration kinetics caused by stronger shearing conditions during spraying contribute to increase the temperature of the pastes. Since the solubility of gypsum and hemihydrate decreases in temperatures above $30{ }^{\circ} \mathrm{C}$ [32] and $\mathrm{C}_{3} \mathrm{~A}$ reactivity is enhanced by the increase in temperature [33], the spraying process may lead to the formation of AFm phases at the moment of accelerator addition. This fact is in accordance with results obtained in isothermal calorimetry. Higher amounts of gypsum in cement may be required to suppress the formation of AFm phases due to the increase in temperature caused by spraying. 


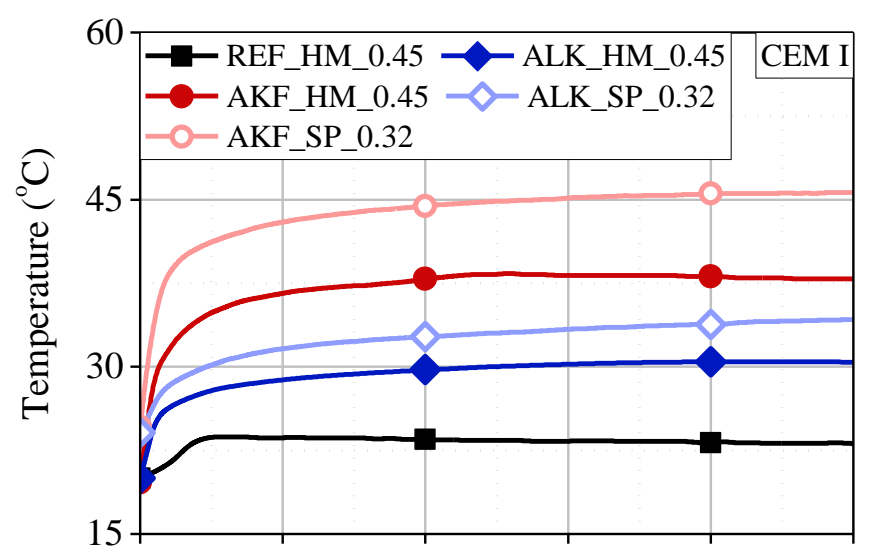

(a)

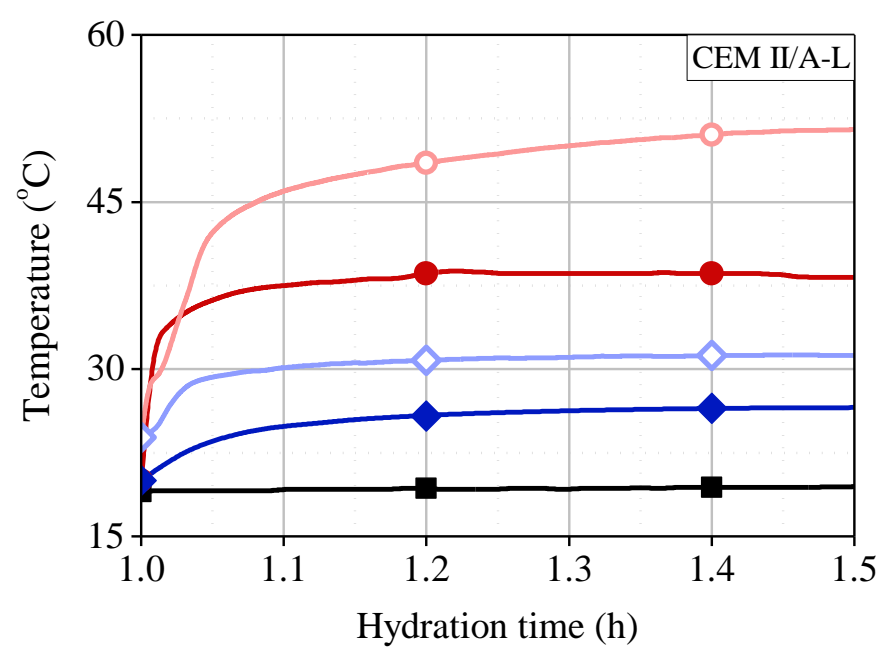

(b)

Figure 5 - Evolution of temperature in CEM I (a) and CEM II/A-L (b) pastes from 1 to $1.5 \mathrm{~h}$.

\subsection{X-ray diffraction}

The evolution of phase composition in hand-mixed and sprayed pastes measured by X-ray diffraction during the first 24 hours is presented in Figure 6. In order to simplify the interpretation of the graphs, only the reacting phases (alite, portlandite and ettringite) are shown. Results obtained with CEM I pastes are grouped on the left and with CEM II/A-L on the right. With the purpose of simplifying the comprehension of the graphs, the difference in alite, portlandite and ettringite contents from accelerator addition until 24 hours is summarized in Table 9. 


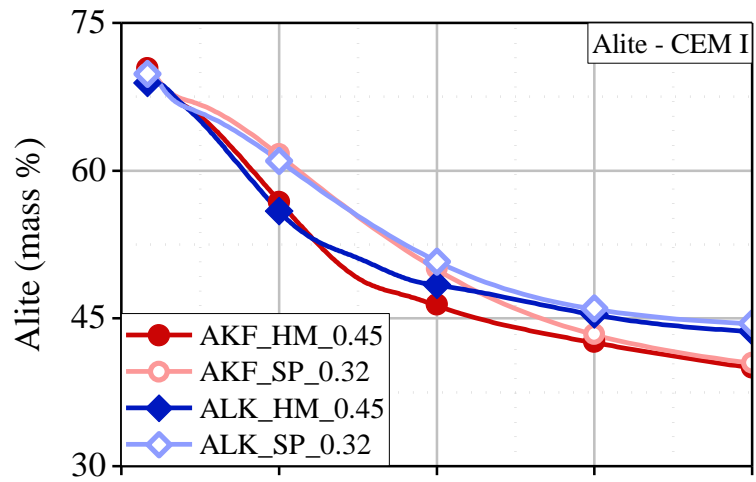

(a)

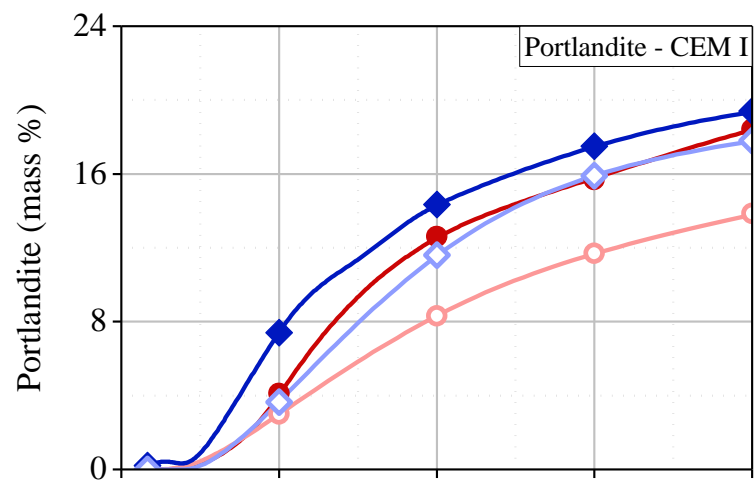

(c)

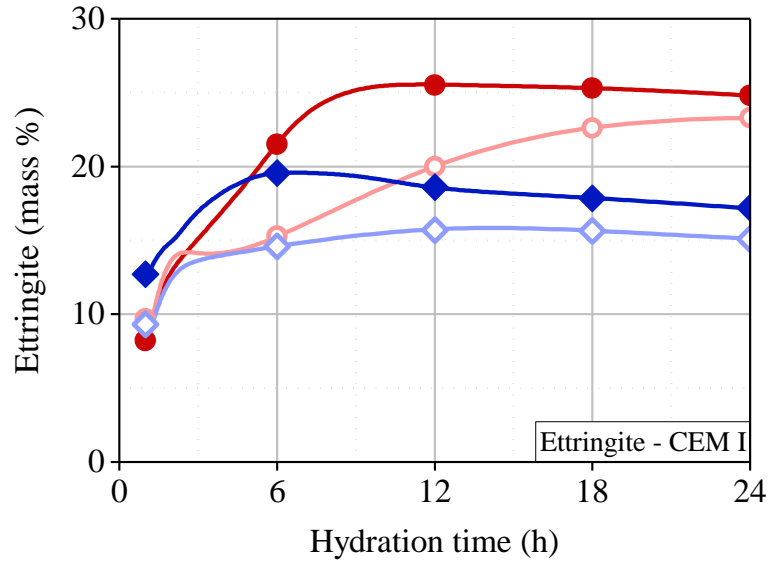

(e)

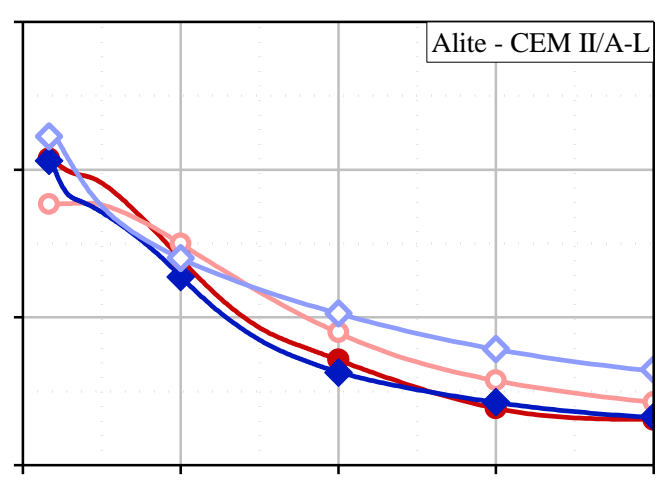

(b)

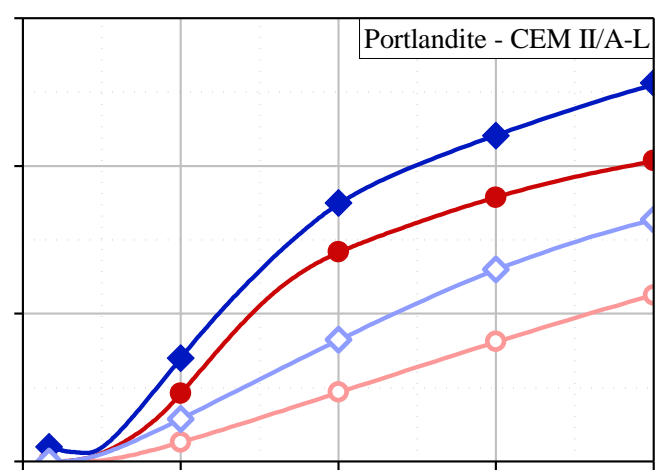

(d)

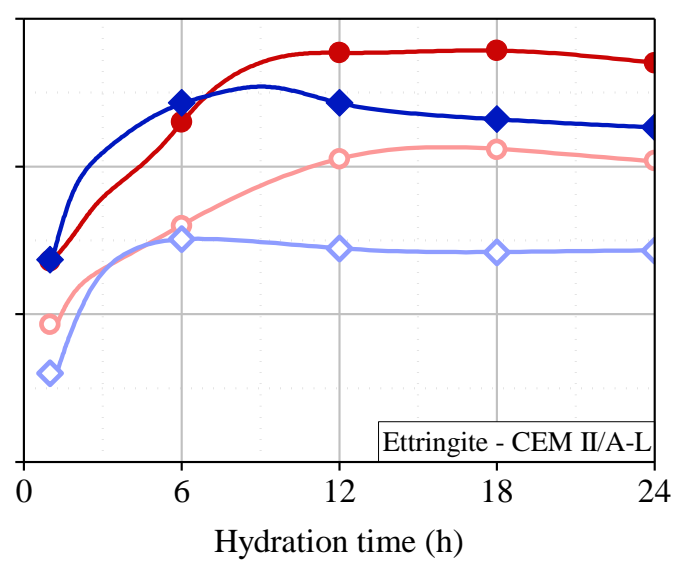

(f)

Figure 6 - Evolution of alite (a and b), portlandite (c and d) and ettringite (e and f) contents from accelerator addition to $24 \mathrm{~h}$.

Table 9 - Variation in alite, portlandite and ettringite contents during the first 24 hours of hydration.

\begin{tabular}{|c|c|c|c|c|c|c|c|c|}
\hline $\begin{array}{c}\text { Variation in phase } \\
\text { content }\end{array}$ & $\begin{array}{c}\text { CEM I_ } \\
\text { AKF_HM } \\
\text { _0.45 }\end{array}$ & $\begin{array}{c}\text { CEM I_ } \\
\text { ALK_HM } \\
\text { 0.45 } \\
\end{array}$ & $\begin{array}{c}\text { CEM_II_ } \\
\text { AKF_HM } \\
\text { 0.45 } \\
\end{array}$ & $\begin{array}{c}\text { CEM II_ } \\
\text { ALK_HM } \\
\text { 0.45 } \\
\end{array}$ & $\begin{array}{c}\text { CEM I_ } \\
\text { AKF_SP } \\
\text { _0.32 }\end{array}$ & $\begin{array}{c}\text { CEM I_ } \\
\text { ALK_SP } \\
\text { _0.32 } \\
\end{array}$ & $\begin{array}{c}\text { CEM II_ } \\
\text { AKF_SP } \\
\text { _0.32 }\end{array}$ & $\begin{array}{c}\text { CEM II } \\
\text { ALK_SP } \\
\text { _0.32 }\end{array}$ \\
\hline $\begin{array}{l}\text { Alite consumed } \\
\text { until } 24 \mathrm{~h}(\%)\end{array}$ & 31.1 & 25.5 & 26.3 & 26.5 & 30.8 & 25.8 & 20.5 & 25.2 \\
\hline $\begin{array}{l}\text { Portlandite formed } \\
\text { until } 24 \mathrm{~h}(\%)\end{array}$ & 19.1 & 19.4 & 16.6 & 20.2 & 14.2 & 18.5 & 9.7 & 14.8 \\
\hline $\begin{array}{l}\text { Ettringite formed } \\
\text { at } 15 \mathrm{~min}(\%)\end{array}$ & 9.9 & 13.3 & 13.9 & 14.8 & 9.7 & 9.3 & 9.3 & 6.0 \\
\hline Ettringite formed & 24.7 & 17.0 & 26.7 & 22.5 & 24.1 & 14.6 & 19.1 & 14.7 \\
\hline
\end{tabular}


The mixing procedure leads to major differences in the evolution of phase composition, although cement pastes produced by both processes have the same mix composition. In hand-mixed pastes, alite hydration proceeds at a larger extent and rate until 24 hours, providing a higher consumption of alite and a consequent formation of larger amounts of portlandite. The differences in phase composition are more sensitive to accelerator type in sprayed pastes. These data are in total agreement with the results obtained from the calorimetric curves.

Ettringite is the main hydrate affected by the mixing process. As observed in Table 9, variations in ettringite contents are more noticeable when the alkaline accelerator is used, because accelerator reaction depends on gypsum dissolution. Ettringite contents in CEM I_ALK_HM_0.45 and CEM II_ALK_HM_0.45 are 30 and $60 \%$ higher than in the equivalent sprayed pastes at 15 minutes, respectively. At 24 hours, hand-mixed CEM I and CEM II pastes with the alkaline accelerator contain 24 and $35 \%$ more ettringite than sprayed pastes with the same accelerator. Regarding the alkali-free accelerator, ettringite amounts in CEM I_AKF_HM_0.45 and CEM II_AKF_HM_0.45 are 2.0 and $33 \%$ larger than the equivalent sprayed pastes at 15 minutes and 2.4 and $29 \%$ larger at 24 hours.

A possible explanation to this fact is that ettringite is formed too rapidly during spraying due to the high shearing conditions achieved in this case. The early-formed aluminate hydrates might present a low degree of crystallinity and be disposed in a gellike structure. A similar outcome was already reported by [34], who observed a gel-like structure in ettringite precipitated at very early ages. Therefore, the lower crystallinity in ettringite in sprayed pastes may be expected, since a short time is available for the nucleation of crystals.

Furthermore, ettringite formed during the spraying process might not be suitably oriented for X-ray diffraction. In the case of needle-like structures, crystals disposed in a diffuse orientation cause the decrease of the intensities of diffracted X-ray beams. The result of the formation of precipitates in a disarranged microstructure is the quantification of lower amounts of ettringite. As far as hydration progresses and once nucleation of ettringite occurs, crystal growth becomes rapid and the X-ray intensity due to ettringite strengthens up. 
To evaluate the composition of aluminate hydrates precipitated in the first hour after accelerator addition, the evolution of $\mathrm{C}_{3} \mathrm{~A}$ and gypsum contents in hand-mixed and sprayed pastes is shown in Table 10 . In sprayed pastes, $\mathrm{C}_{3} \mathrm{~A}$ hydration is favored and less gypsum is consumed from 15 minutes to 1 hour than in hand-mixed pastes. The $\mathrm{C}_{3} \mathrm{~A} / \mathrm{gypsum}$ ratio in the hydrates formed from 15 minutes to 1 hour, considering that all gypsum was consumed during $\mathrm{C}_{3} \mathrm{~A}$ hydration, is higher in sprayed pastes. This indicates that the formation of AFm phases is advanced and may take place during the accelerator peak, lowering ettringite contents in sprayed pastes.

Table $10-\mathrm{C}_{3} \mathrm{~A}$ and gypsum evolution in the first hour after accelerator addition.

\begin{tabular}{|c|c|c|c|c|c|c|c|c|}
\hline Phase content & $\begin{array}{c}\text { CEM I- } \\
\text { AKF_HM } \\
\text { 0.45 } \\
\end{array}$ & $\begin{array}{c}\text { CEM I_ } \\
\text { ALK_HM } \\
\mathbf{0 . 4 5} \\
\end{array}$ & $\begin{array}{c}\text { CEM II_ } \\
\text { AKF_HM } \\
\quad 0.45 \\
\end{array}$ & $\begin{array}{c}\text { CEM II_- } \\
\text { ALK_HM } \\
\mathbf{0 . 4 5} \\
\end{array}$ & $\begin{array}{c}\text { CEM I_ } \\
\text { AKF_SP } \\
\quad 0.32 \\
\end{array}$ & $\begin{array}{c}\text { CEM I_ } \\
\text { ALK_SP } \\
\text { 0.32 } \\
\end{array}$ & $\begin{array}{c}\text { CEM II } \\
\text { AKF_SP } \\
\quad 0.32 \\
\end{array}$ & $\begin{array}{c}\text { CEM II } \\
\text { ALK_SP } \\
\ldots 0.32 \\
\end{array}$ \\
\hline $\mathrm{C}_{3} \mathrm{~A}$ at $15 \min (\%)$ & 2.3 & 2.1 & 1.5 & 1.8 & 2.8 & 3.0 & 3.1 & 3.1 \\
\hline $\mathrm{C}_{3} \mathrm{~A}$ at $1 \mathrm{~h}(\%)$ & 2.1 & 1.9 & 1.4 & 1.7 & 2.5 & 2.6 & 2.8 & 2.6 \\
\hline $\begin{array}{c}\text { Gypsum at } 15 \mathrm{~min} \\
(\%)\end{array}$ & 4.7 & 1.5 & 3.8 & 3.2 & 2.0 & 1.0 & 2.0 & 2.0 \\
\hline Gypsum at $1 \mathrm{~h}(\%)$ & 3.8 & 0.0 & 3.1 & 1.3 & 1.2 & 0.0 & 1.5 & 1.3 \\
\hline $\begin{array}{l}\mathrm{C}_{3} \mathrm{~A} / \text { gypsum ratio in } \\
\text { hydrates formed from } \\
15 \mathrm{~min} \text { to } 1 \mathrm{~h}\end{array}$ & 0.22 & 0.13 & 0.14 & 0.05 & 0.38 & 0.40 & 0.60 & 0.71 \\
\hline
\end{tabular}

This process is more evident when the alkaline accelerator is used and in the pastes containing CEM II/A-L. This result confirms the hypothesis about the absence of the dissociated peak in the calorimetric curves of sprayed pastes with alkaline accelerator. Indeed, this may be attributed to the concurrent formation of ettringite and AFm during the accelerator peak. It may also be a consequence of the higher temperatures achieved during spraying, as described in section 3.2.

\subsection{TGA}

Results corresponding to the quantification of portlandite and chemically bound water by thermogravimetry are shown in Table 11. A clear influence of the mixing process on the hydration behavior of cement pastes is observed. Hand-mixed pastes contain more portlandite and chemically bound water than sprayed pastes, leading to 
higher degrees of hydration during the period analyzed. These data corroborate the results obtained in isothermal calorimetry and X-ray diffraction.

Table 11 - Portlandite and chemically bound water quantified by thermogravimetry.

\begin{tabular}{|c|c|c|c|c|c|}
\hline Compound & Age & $\begin{array}{c}\text { CEM I_AKF } \\
\text { _HM_0.45 }\end{array}$ & $\begin{array}{c}\text { CEM I_ALK } \\
\text { HM_0.45 } \\
\end{array}$ & $\begin{array}{c}\text { CEM I_AKF } \\
\text { _SP_0.32 }\end{array}$ & $\begin{array}{c}\text { CEM I_ALK } \\
\text { _SP_0.32 }\end{array}$ \\
\hline \multirow{4}{*}{$\begin{array}{l}\text { Portlandite } \\
\qquad(\%)\end{array}$} & $15 \mathrm{~min}$ & 2.41 & 1.93 & 2.28 & 1.65 \\
\hline & $3 \mathrm{~h}$ & 3.00 & 3.14 & 2.55 & 1.69 \\
\hline & $12 \mathrm{~h}$ & 10.79 & 14.00 & 9.39 & 10.76 \\
\hline & $48 \mathrm{~h}$ & 17.37 & 18.00 & 14.67 & 15.21 \\
\hline \multirow{4}{*}{$\begin{array}{c}\text { Chemically } \\
\text { bound } \\
\text { water }(\%)\end{array}$} & $15 \mathrm{~min}$ & 3.82 & 3.39 & 3.72 & 2.79 \\
\hline & $3 \mathrm{~h}$ & 4.69 & 4.43 & 4.17 & 2.46 \\
\hline & $12 \mathrm{~h}$ & 10.18 & 10.83 & 9.74 & 8.82 \\
\hline & $48 \mathrm{~h}$ & 17.79 & 14.73 & 14.53 & 13.24 \\
\hline
\end{tabular}

Sprayed pastes contain portlandite amounts between $5 \%$ and $15 \%$ lower than the equivalent hand-mixed pastes at the same age. This may be attributed to the inhibition in alite hydration caused by the massive precipitation of aluminate hydrates when accelerator is added. Such effect is more pronounced in sprayed pastes due to the better homogenization of cement and accelerator and becomes more evident as hydration proceeds.

The same trend is observed regarding the quantification of chemically bound water. Sprayed pastes CEM I_AKF_SP_0.32 and CEM I_ALK_SP_0.32 present 10 and $18 \%$ less chemical bound water at 15 minutes than the equivalent hand-mixed pastes. Those differences become respectively 21 and $10 \%$ at 48 hours and indicate that alite hydration proceeds slower in sprayed pastes.

For both types of accelerators, larger amounts of chemically bound water were expected in sprayed pastes at 15 minutes due to faster initial rates of reaction. However, accelerator reaction reaches its maximum 3 minutes after its addition (see Figure 3.c and Figure 3.d) and the difference between mixing processes may reduce in the course of the 12 minutes left to reach the first time interval. In addition to that, the temperature range between 50 and $200{ }^{\circ} \mathrm{C}$ comprehends the dehydration of ettringite, AFm phases, $\mathrm{C}-\mathrm{S}-\mathrm{H}$, gypsum and hemihydrate and it is not possible to quantify how much water 
corresponds to each phase. Anyhow, it is possible to conclude that sprayed pastes have smaller amounts of C-S-H since they contain lower contents of portlandite.

Although AFm phases cannot be quantified properly by TGA, their presence in the sprayed paste with the alkaline accelerator (CEM I_ALK_SP_0.32) at 15 minutes of hydration may be detected. As observed in Figure 7, the DTG curve presents two shoulders around 138 and $180{ }^{\circ} \mathrm{C}$ related to the formation of monosulfoaluminate, which was also observed by [35]. In addition, the shoulder around $250{ }^{\circ} \mathrm{C}$ corresponding to the water loss from the dehydroxylation of the aluminum hydroxide column in ettringite [36] is only observed in the hand-mixed paste.

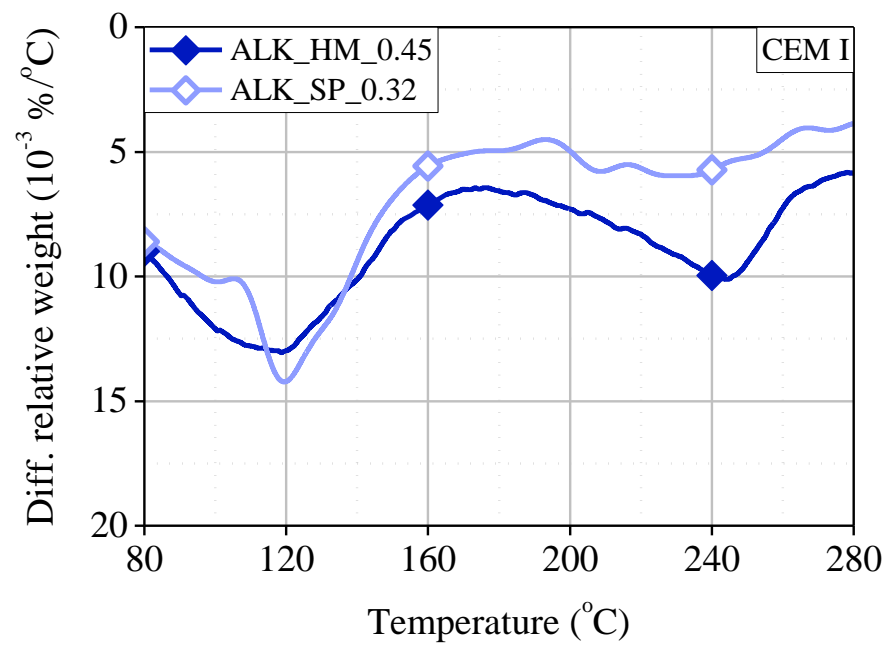

Figure 7 - DTG curves of CEM I_ALK_HM_0.45 and CEM I_ALK_SP_0.32 pastes at 15 min of hydration.

These observations indicate that the high shearing conditions achieved during spraying induce the formation of AFm phases. They are associated with the enhanced aluminate reactivity and low sulfate availability in the paste with the alkaline accelerator (high final $\mathrm{C}_{3} \mathrm{~A} / \mathrm{SO}_{3}$ ratio). These processes validate the analysis of the accelerator peak in the calorimetric curves.

The quantification of portlandite differs in TGA and XRD measurements. Until 3 hours of hydration, the low amounts of portlandite are not detectable by XRD, while TGA provides results that are more satisfactory. At latter ages, portlandite contents determined by XRD are larger than in TGA because the crystalline content of phases are considered as $100 \%$ in the former (notice that in TGA, amorphous and crystalline phases are not distinguishable). 


\subsection{SEM and EDS microanalysis}

Results obtained in the SEM analysis are presented from Figure 8 to Figure 11. The regions analyzed by EDS are indicated by a yellow circle in the corresponding image. Results obtained in the EDS spectra are represented as the relative intensities of each element, placed above each image. The peaks considered to measure the intensity of $\mathrm{Ca}, \mathrm{Si}, \mathrm{Al}, \mathrm{S}$ and $\mathrm{Na}$ are correspondent to the energies of $3.73,1.78,1.52,2.33$ and $1.1 \mathrm{keV}$, respectively.

SEM images of the hand-mixed CEM I pastes with the alkali-free accelerator at $15 \mathrm{~min}, 3 \mathrm{~h}$ and $12 \mathrm{~h}$ are presented in Figure 8.a, b and c, respectively. Likewise, the equivalent sprayed pastes are shown in Figure 9. 


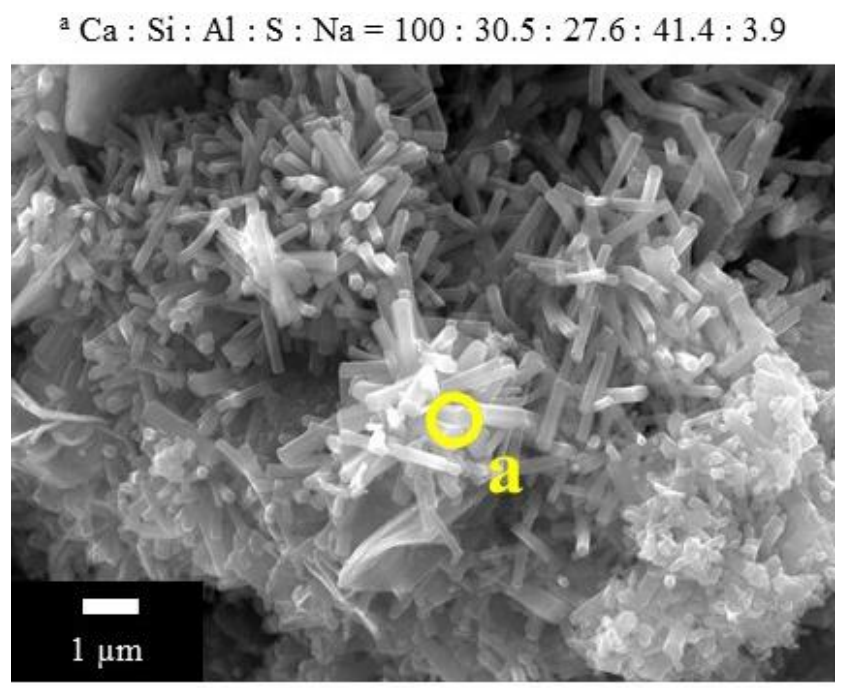

(a)

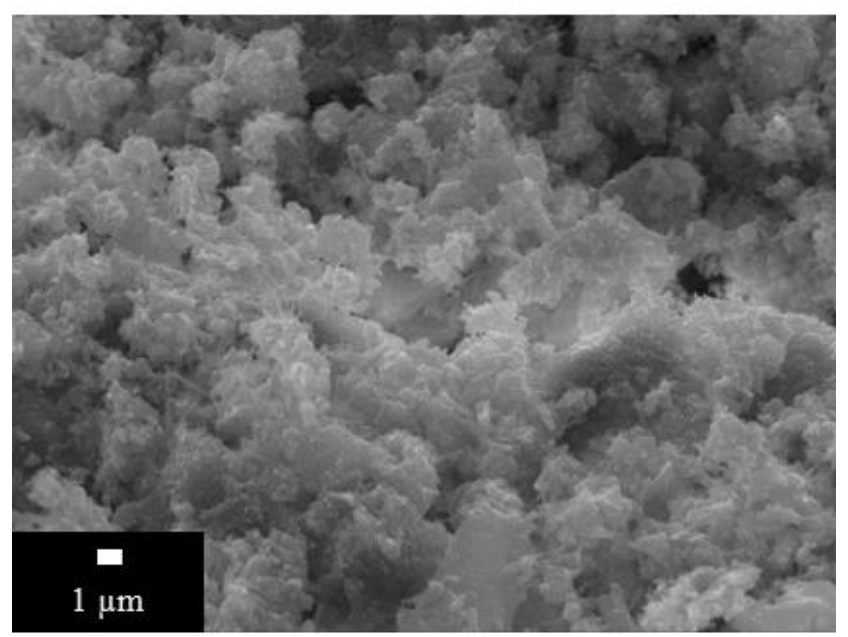

(b)

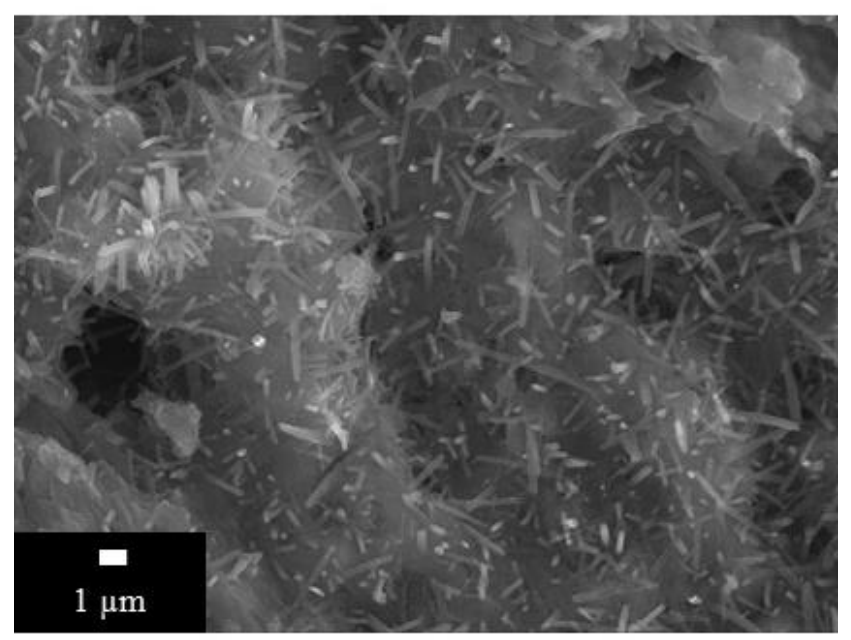

(c)

Figure 8 - CEM I_AKF_HM_0.45 pastes at 15 min with the corresponding EDS spectrum (a), at $3 \mathrm{~h}$ (b) and at $12 \mathrm{~h}(\mathrm{c})$. 
${ }^{\text {a }} \mathrm{Ca}: \mathrm{Si}: \mathrm{Al}: \mathrm{S}: \mathrm{Na}=100: 24.6: 18.0: 19.3: 2.5$

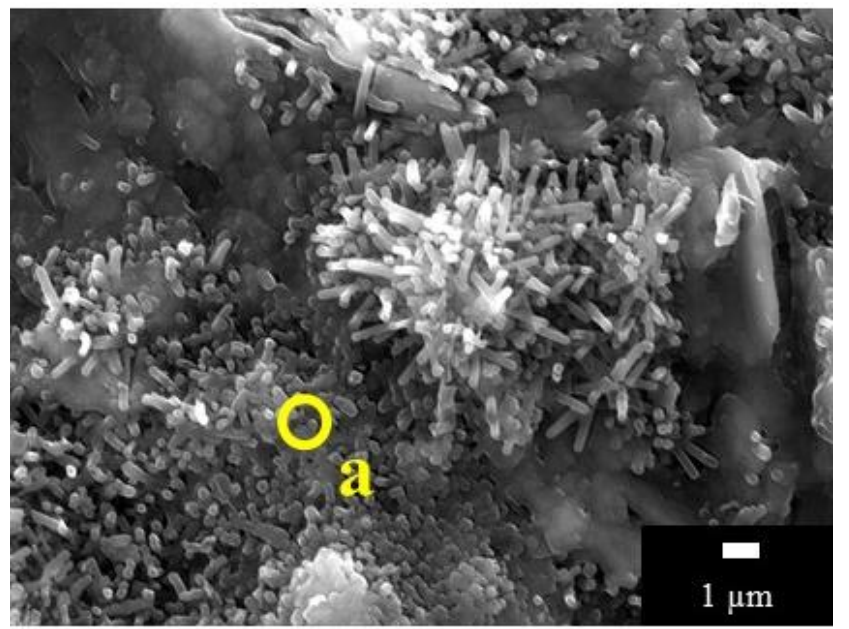

(a)

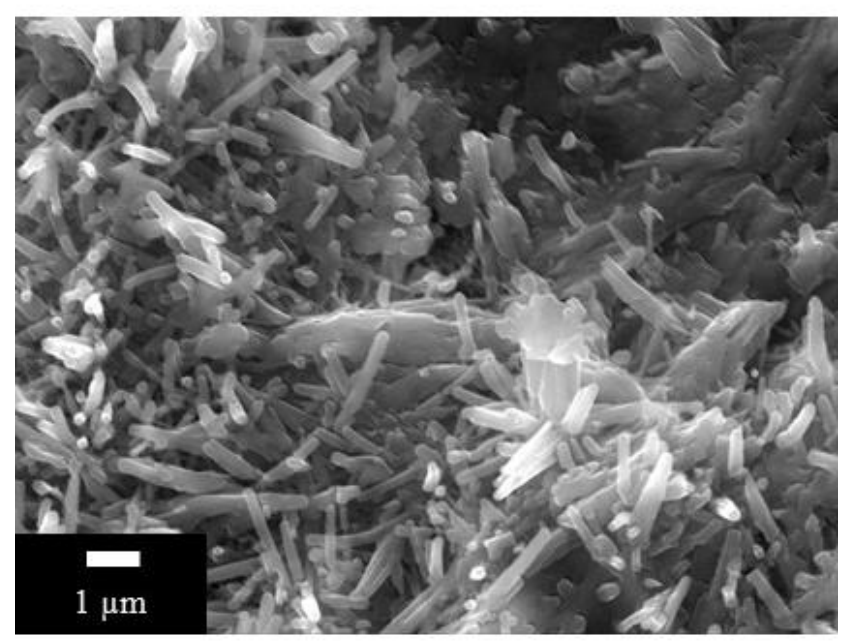

(b)

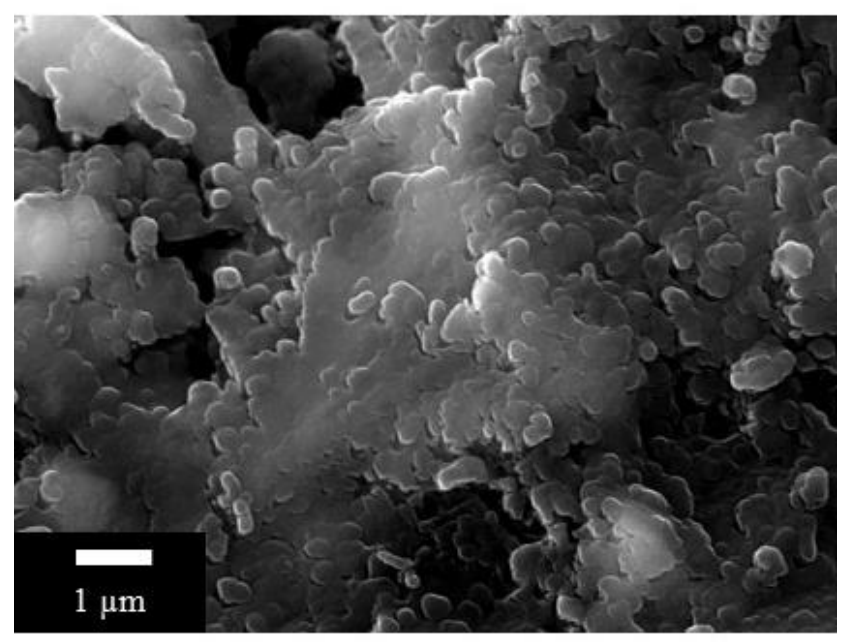

(c)

Figure 9 - CEM I_AKF_SP_0.32 pastes at 15 min with the corresponding EDS spectrum (a), at $3 \mathrm{~h}$ (b) and at $12 \mathrm{~h}(\mathrm{c})$. 
Hydration progressed extensively until 15 minutes in the hand-mixed paste (Figure 8.a), as reflected by the large amount of hydration products precipitated on the grain surface. A great number of ettringite crystals measuring around $2 \mu \mathrm{m}$ in length can be observed. This hydrate nucleates and precipitates as hexagonal needle-like crystals with flat terminations in an ordered structure. The $\mathrm{Al} / \mathrm{S}$ ratio found in the region analyzed is equal to 0.667 , which is the exact value found in pure ettringite.

The sprayed paste at the same age (Figure 9.a) presents a less organized microstructure, composed mainly by less-regularly-formed and highly dispersed aluminate hydrates. Ettringite needles present rounded terminations and are approximately $1.5 \mu \mathrm{m}$-long ( $25 \%$ shorter than the crystals formed in hand-mixed pastes at the same age). The difference in morphology is caused by the faster accelerator reaction during spraying. The region analyzed by EDS has an $\mathrm{Al} / \mathrm{S}$ ratio equal to 0.93 , which indicates the coexistence of AFt and AFm phases precipitated on a cement grain surface.

At 3 hours of hydration, the microstructure is denser and a larger area is covered by hydration products (mainly C-S-H and AFt in Figure 8.b). In sprayed pastes (Figure 9.b), ettringite needles have grown and measure approximately $2 \mu \mathrm{m}$ in length. In spite of that, their morphology does not present the same arrangement as in hand-mixed pastes, being still characterized by diffusely oriented needles. Such outcome corroborates the hypothesis described in section 3.3 and the data obtained in XRD (the disarranged microstructure leads to the quantification of smaller amounts of ettringite by XRD).

Figure 8.c shows a great number of ettringite crystals on a cement grain surface at 12 hours of hydration in hand-mixed pastes. In the case of sprayed pastes (Figure 9.c), cement grains present a large surface covered by C-S-H and aluminate hydrates. The formation of highly dispersed ettringite and other aluminate hydrates may decrease the rate of alite dissolution and limit further hydration due to space filling. That is a plausible explanation on why sprayed pastes with the alkali-free accelerator present a lower degree of hydration than the hand-mixed ones. Such results are in line with the observations derived from the analysis of the energy release curves in isothermal calorimetry (Figure 4).

Figure 10 and Figure 11 present SEM images of hand-mixed and sprayed CEM I pastes with the alkaline accelerator, respectively. At 15 minutes of hydration, a large amount of hydrated phases is deposited on the surface of a cement grain (Figure 10.a). 
According to the EDS spectrum, the hydrates present $\mathrm{Al} / \mathrm{Ca}, \mathrm{Si} / \mathrm{Ca}$ and $\mathrm{Al} / \mathrm{S}$ ratios equal to $0.62,0.168$ and 6.7 , respectively, indicating they might be composed by $\mathrm{C}-\mathrm{A}-\mathrm{H}$ and AFm phases, with low contents of C-S-H. They are formed by the fast reaction of the accelerator with calcium ions, as well as by $\mathrm{C}_{3} \mathrm{~A}$ hydration in a medium with limited sulfate content. In sprayed pastes at the same age (Figure 11.a), the formation of aluminate hydrates over the cement grains surface can also be observed. These hydrates present an $\mathrm{Al} / \mathrm{S}$ ratio equal to 1.35 and may be composed mainly by $\mathrm{AFm}$ phases. 


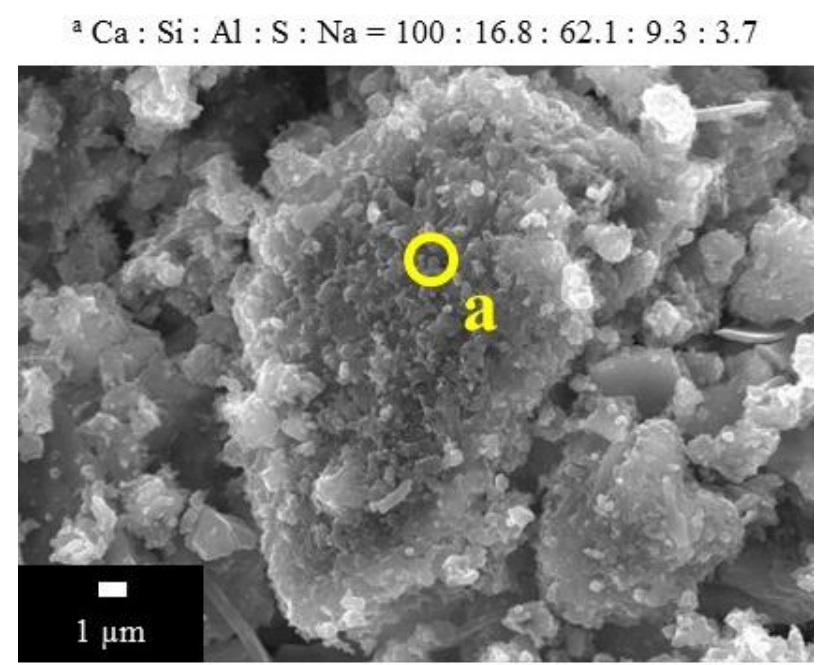

(a)

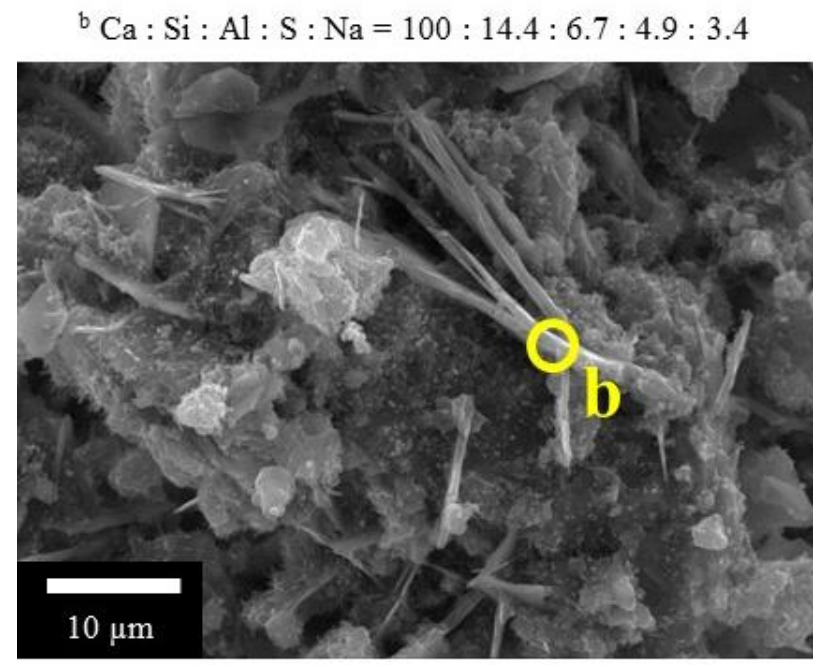

(b)

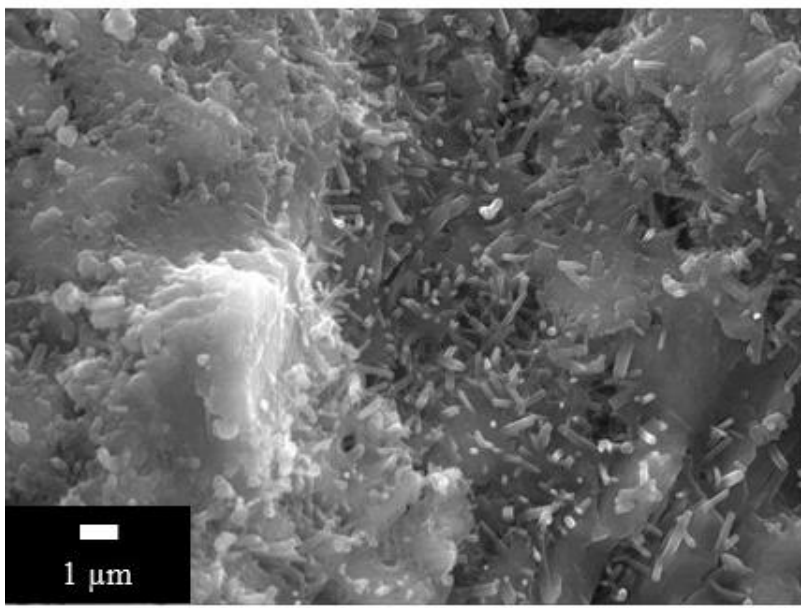

(c)

Figure 10 - CEM I_ALK_HM_0.45 pastes at 15 min with the corresponding EDS spectrum (a), at $3 \mathrm{~h}$ with the corresponding EDS spectrum (b) and at $12 \mathrm{~h}$ (c). 


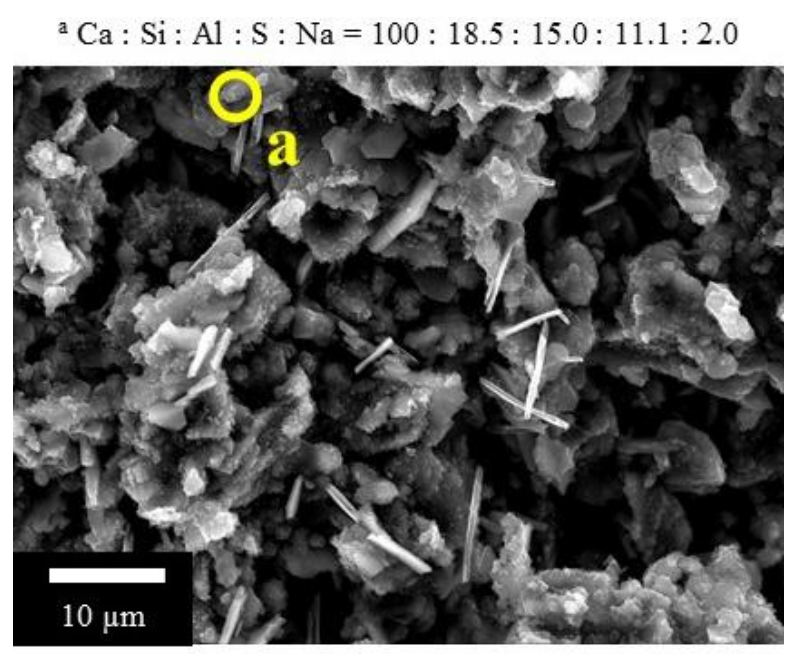

(a)

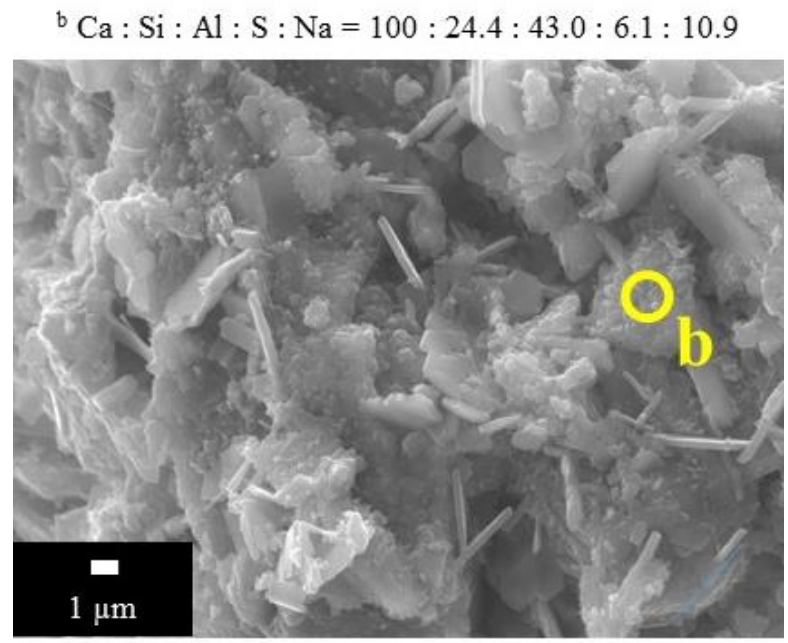

(b)

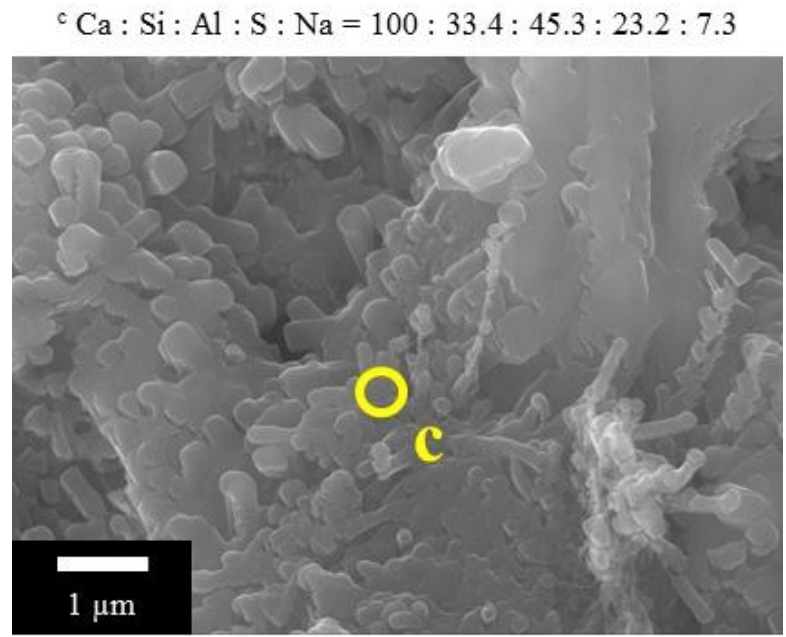

(c)

Figure 11 - CEM I_ALK_SP_0.32 pastes at $15 \mathrm{~min}$ (a), $3 \mathrm{~h}$ (b) and $12 \mathrm{~h}$ (c), with the corresponding EDS spectra. 
A fast progression in hydration can be observed at 3 hours in both hand-mixed and sprayed pastes (Figure 10.b and Figure 11.b). Hydrates formed in sprayed pastes are hexagonal plates presenting an $\mathrm{Al} / \mathrm{S}$ ratio equal to 7.0 and an elevated sodium content. This aluminate hydrate may be an AFm phase denominated U-phase and was also reported by [37-39] in cement systems containing sodium concentration above 0.40 mol/L. The sprayed paste CEM I_ALK_SP_0.32 presents a propitious sodium concentration in the liquid phase for U-phase formation $(0.58 \mathrm{~mol} / \mathrm{L}$, Table 5).

The mixing procedure influences the morphology and the dispersion of this AFm phase significantly. This hydrate presents diameters varying from 12 to $40 \mu \mathrm{m}$ and tends to agglomerate in hand-mixed pastes (Figure 10.b). However, the average diameter in sprayed pastes is $3 \mu \mathrm{m}$ and its dispersion is fairly homogeneous (Figure 11.b). This difference in microstructure is caused by the high shearing conditions during spraying, similarly to the pastes with the alkali-free accelerator.

At 12 hours of hydration in hand-mixed pastes (Figure 10.c), AFt hydrates appear throughout the matrix and are localized in certain regions. In sprayed pastes (Figure 11.c), hydrates are more uniformly distributed in the whole matrix and present an $\mathrm{Al} / \mathrm{S}$ ratio equal to 2.0, being composed by AFm and $\mathrm{C}-\mathrm{A}-\mathrm{H}$ phases. According to [2], AFm and C-A-H phases precipitated on the surface of a cement grain contribute to reduce the degree of hydration of alite in alkaline accelerated pastes. This fact justifies the smaller hydration degree measured at 24 hours in sprayed pastes.

\section{Considerations regarding sprayed concrete}

The experimental campaign conducted dealt with the comparison of hand-mixed and sprayed pastes in a laboratory scale. Cement pastes were employed to avoid the influence of aggregates on hydration kinetics and on the microstructure of the matrix. By doing so, results were based purely on the chemistry of cements and accelerators and on the mixing procedure.

Hydration behavior and microstructure in conventionally mixed and sprayed concrete may differ from the results obtained with pastes, due to four main reasons:

a) Equipment used for spraying concrete is more powerful than the small-scale equipment developed for this study. Then, shearing conditions are stronger, which may increase reaction rates [1]. 
b) Aggregates also improve shearing conditions and accelerate cement hydration, as observed by [8]. They may also act as nucleation sites for the precipitation of hydrated phases, influencing the microstructure development.

c) Aggregates dilute cement and accelerator and, therefore, concrete is a less reactive system than cement pastes. Therefore, the temperature reached during hydration is lower than in pastes and may alter the composition of the hydrated phases and the porosity of the matrix significantly [12].

d) Coarse aggregates generate a high impact energy during spraying, which improves the consolidation of the matrix and alters its microstructure. In addition, coarse aggregates rebound during concrete spraying and produce a cement-rich layer between the substrate and the concrete, causing heterogeneities in the microstructure of the matrix [40].

\section{Conclusions}

The following conclusions may be drawn from the results obtained in this experimental program:

- As a general conclusion, spraying enhances accelerator reactivity and accelerates $\mathrm{C}_{3} \mathrm{~A}$ hydration. Consequently, it limits alite dissolution and further hydration, leading to lower degrees of reaction at later ages.

- The rate of accelerator reaction is transport controlled. In sprayed pastes, aluminate ions from the accelerator react at a faster rate than in hand-mixed pastes. This is the result of the optimized diffusion and homogenization of the accelerator in the matrix.

- Accelerators consume sulfate ions from the liquid phase and lead to accelerated $\mathrm{C}_{3} \mathrm{~A}$ reactions. Therefore, the formation of $\mathrm{AFm}$ phases is advanced and may take place before the onset of alite hydration. Spraying intensifies this process due to increased accelerator reactivity and to higher temperatures achieved during mixing. The early formation of AFm phases is more pronounced in pastes characterized by elevated $\mathrm{C}_{3} \mathrm{~A} / \mathrm{SO}_{3}$ ratios, such as in matrices containing alkaline accelerators. 
- Faster kinetics of accelerator and $\mathrm{C}_{3} \mathrm{~A}$ reactions generated by spraying suppress alite hydration. The early formed aluminate hydrates fill up the space available more quickly and decrease the extent and rate of alite hydration due to a lack of space. Consequently, this process diminishes the amount of portlandite formed and leads to lower degrees of hydration in sprayed pastes.

- The mixing process greatly influences the microstructure of the matrix. In sprayed pastes, aluminate hydrated phases are more uniformly distributed throughout the whole matrix. In addition, ettringite is found in a disarranged microstructure and is composed by shorter, less-regularly-formed and highly dispersed needle-like crystals. The difference in morphology is attributed to the high shearing conditions imposed by the spraying process, causing a high diffusion of the accelerator and not providing enough time for the crystals to nucleate and orientate properly. Since part of the ettringite crystals is not crystalline or not suitably oriented for X-ray diffraction, quantitative measurements using this technique provide lower ettringite contents.

- Spraying provides a higher sensitivity in the analysis of different accelerators and is recommended especially in the case of alkaline formulations. However, the evaluation of different cementitious systems with the same accelerator may be performed in hand-mixed pastes.

- Hand-mixing of accelerators is sufficiently representative for the evaluation of hydration in isothermal calorimetry. However, XRD, TGA and SEM should be preferentially conducted in sprayed pastes in order to obtain a more representative quantification of the phases formed and to analyze variations in hydration mechanisms caused by the mixing process.

\section{Acknowledgements}

The first author would like to thank CAPES (CAPES Foundation, Ministry of Education of Brazil, process 2726/13-0) for the scholarship granted. Thanks are extended to Industrias Químicas del Ebro, to Centro para el Desarrollo Industrial (CDTi) and to the Ministerio de Economía y Competitividad (project IDI-20130248) for technical and financial support. We also thank Dr. Xavier Alcobé for his support during the XRD experiments. 


\section{APPENDIX 1}

In order to compare how the w/c ratio influences the hydration of accelerated hand-mixed pastes, heat flow curves of pastes containing w/c ratios of 0.45 and 0.32 are compared in figure A.1. All the materials used and admixtures dosages are described in section 2.2.

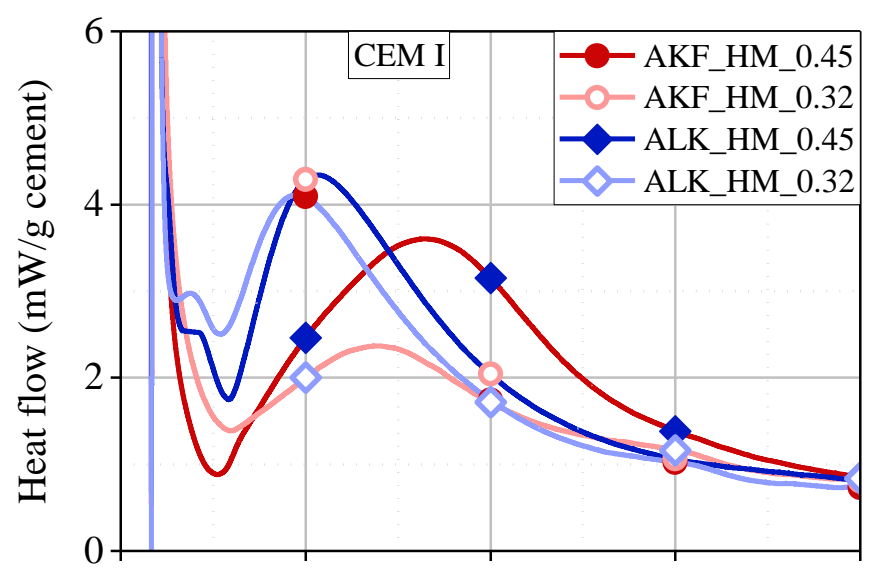

(a)

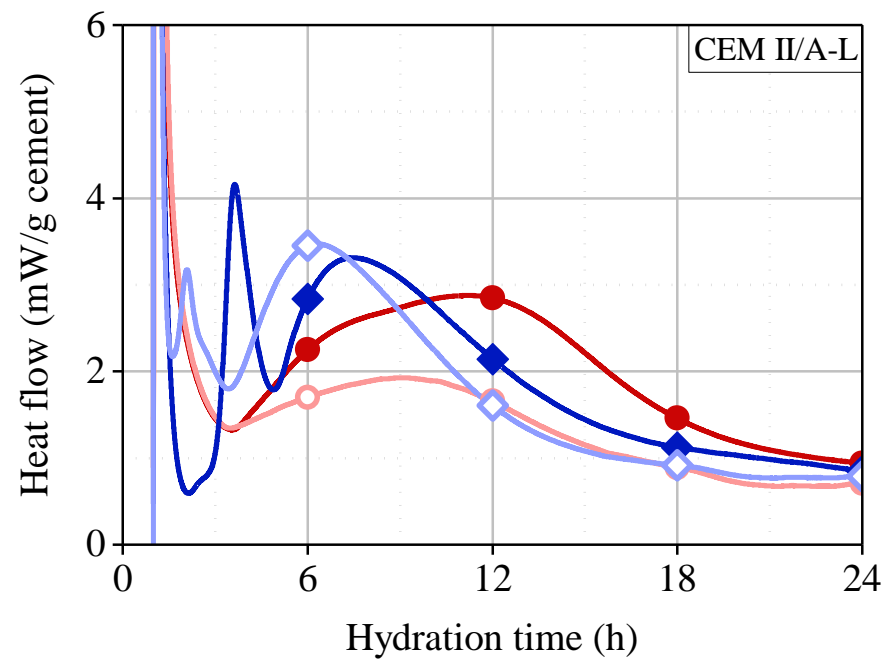

(b)

Figure A.1 - Heat flow curves obtained with hand-mixed pastes using w/c ratios of 0.32 and 0.45 with CEM I (a) and CEM II/A-L (b).

Pastes produced with the w/c equal to 0.32 present a small reduction in induction periods and in the maximum intensity of the main hydration peak for both types of cement and accelerators. However, no difference in hydration mechanisms were observed. For this reason, the differences in hydration behavior observed in sprayed and 
hand-mixed pastes may be associated exclusively to the mixing process, disregarding the effect of the lower w/c ratio in sprayed pastes.

\section{References}

[1] I. Galobardes, Characterization and control of wet-mix sprayed concrete with accelerators. Ph.D. Thesis (2013).

[2] R.P. Salvador, S.H.P. Cavalaro, I. Segura, A.D. Figueiredo, J. Pérez, Early age hydration of cement pastes with alkaline and alkali-free accelerators for sprayed concrete, Constr. Build. Mater. 111 (2016) 386-398. doi:10.1016/j.conbuildmat.2016.02.101.

[3] J.M. Martínez, Estudio de las variables en el proceso de producción de morteros con acelerante de fraguado. Master Thesis (2013).

[4] I. Galobardes, S.H. Cavalaro, A. Aguado, T. Garcia, Estimation of the modulus of elasticity for sprayed concrete, Constr. Build. Mater. 53 (2014) 48-58. doi:10.1016/j.conbuildmat.2013.11.046.

[5] P. Juilland, Early hydration of cementitious systems. Ph.D. Thesis (2009).

[6] Q. Xu, J. Stark, Early hydration of ordinary Portland cement with an alkaline accelerator. Advances in Cement Research, 17 (2005) 1-8.

[7] T.P. DiNoia, P.J. Sandberg, Alkali-free shotcrete accelerator interactions with cement and admixtures in Shotcrete: Engineering Developments, 2004, 137-144.

[8] P. Juilland, A. Kumar, E. Gallucci, R.J. Flatt, K.L. Scrivener, Effect of mixing on the early hydration of alite and OPC systems, Cem. Conc. Res. 42 (2012) 1175-1188. doi:10.1016/j.cemconres.2011.06.011.

[9] B. Lagerblad, L.E. Bryne, Texture and bond at the interfacial between hard rock and sprayed concrete at early age hardening time. In: $7^{\text {th }}$ International Symposium on Sprayed Concrete. Sandefjord, Norway, June/2014: pp. 255-265.

[10] B. Lindlar, L. Oblak, D, Lootens, C. Stenger, From tunnel to laboratory: Scaling of shotcrete testing. In: $7^{\text {th }}$ International Symposium on Sprayed Concrete. Sandefjord, Norway, June/2014: pp. 282-286. 
[11] B. Lothenbach, G.L. Saout, E. Gallucci, K.L. Scrivener, Influence of limestone on the hydration of Portland cements, Cem. Concr. Res. 38 (2008) 848-860. doi:10.1016/j.cemconres.2008.01.002.

[12] B. Lothenbach, T. Matschei, G. Möschner, F.P. Glasser, Thermodynamic modelling of the effect of temperature on the hydration and porosity of Portland cement, Cem. Concr. Res. 38 (2008) 1-18. doi:10.1016/j.cemconres.2007.08.017.

[13] H.F.W. Taylor, Cement Chemistry. $2^{\text {nd }}$ ed. Thomas Telford Publishing, 1997.

[14] AENOR. UNE-EN 196-2:2006. Methods of testing cement - Part 2: Chemical analysis of cement, 2006.

[15] J. Woodward, An introduction to geotechnical processes. $1^{\text {st }}$ ed. Spon Press, 2005.

[16] A.G. de la Torre, S. Bruque, J. Campo, M.A.G. Aranda, The superstructure of $\mathrm{C}_{3} \mathrm{~S}$ from synchrotron and neutron powder diffraction and its role in quantitative analysis, Cem. Conc. Res. 32 (2002) 1347-1356.

[17] T. Tsurumi, Y. Hirano, H. Kato, T. Kamiya, M. Daimon, Crystal structure and hydration of belite, Ceramic Transactions 40 (1994) 19-25.

[18] P. Mondal, J.W. Jeffery, The crystal structure of tricalcium aluminate, $\mathrm{Ca}_{3} \mathrm{Al}_{2} \mathrm{O}_{6}$. Acta Cryst. B31 (1975) 689-697.

[19] A.A. Colville, S. Geller, The crystal structure of brownmillerite, $\mathrm{Ca}_{2} \mathrm{FeAlO}_{5}$. Acta Cryst, B27 (1971) 2311-2315.

[20] A.G. de la Torre, M.G. Lopez-Olmo, C. Alvarez-Rua, S.G. Granda, M.A.G. Aranda, Structure and microstructure of gypsum and its relevance to Rietveld quantitative phase analyses, Powder Diffraction 19 (2004) 240-246.

[21] R. Wartchow, Datensammlung nach der "learnt profile"-methode(LP) für calcit und vergleich mit der "background peak background"-methode (BPB), Zeit. Kristall. 186 (1989) 300-302.

[22] H.E. Petch, The hydrogen positions in portlandite, $\mathrm{Ca}(\mathrm{OH})_{2}$, as indicated by the electron distribution, Acta Cryst. 14 (1961) 950-957.

[23] F. Goetz-Neunhoeffer, J. Neubauer, Refined ettringite structure for quantitative Xray diffraction analysis, Powder Diffraction 21 (2006) 4-11. 
[24] R. Allmann, Die Doppelschichtstruktur der plaettchenfoermigen CalciumAluminium-H Salze am Beispiel des $(\mathrm{CaO}) 3 \cdot \mathrm{Al}_{2} \mathrm{O}_{3} \cdot \mathrm{CaSO}_{4}\left(\mathrm{H}_{2} \mathrm{O}\right)_{12}$, Neues Jahrbuch fuer Mineralogie (1968) 140-144.

[25] T. Runcevski, R.E. Dinnebier, O.V. Magdysyuk, H. Poellmann, Crystal structures of calcium hemicarboaluminate and carbonated calcium hemicarboaluminate from synchrotron powder diffraction data, Acta Crystallographica, Section B: Structural Science 68 (2012) 493-500.

[26] M. François, G. Renaudin, O. Evrard, A cementitious compound with composition $3 \mathrm{CaO} \cdot \mathrm{Al}_{2} \mathrm{O}_{3} \cdot \mathrm{CaCO}_{3} \cdot 11 \mathrm{H}_{2} \mathrm{O}$, Acta Crystallographica, Section C: Crystal Structure Communications 54 (1998) 1214-1217.

[27] J. Zhang, G.W. Scherer, Comparison of methods for arresting hydration of cement, Cem. Conc. Res. 41 (2011) 1024-1036. doi:10.1016/j.cemconres.2011.06.003.

[28] I. Pane, W. Hansen, Investigation of blended cement hydration by isothermal calorimetry and thermal analysis, Cem. Conc. Res. 35 (2005) 1155-1164. doi:10.1016/j.cemconres.2004.10.027.

[29] R.P. Salvador, S.H.P. Cavalaro, A. Rueda, A.D. Figueiredo, Effect of cement composition on the reactivity of alkali-free accelerating admixtures for shotcrete. In: $7^{\text {th }}$ International Symposium on Sprayed Concrete. Sandefjord, Norway, June/2014: pp. 350-360.

[30] A. Quennoz, K.L. Scrivener, Interactions between alite and $\mathrm{C}_{3} \mathrm{~A}$-gypsum hydrations in model cements, Cem. Conc. Res. 44 (2013) 46-54. doi:10.1016/j.cemconres.2012.10.018.

[31] H. Minard, S. Garrault, L. Regnaud, A. Nonat, Mechanisms and parameters controlling the tricalcium aluminate reactivity in the presence of gypsum, Cem. Conc. Res. 37 (2007) 1418-1426. doi:10.1016/j.cemconres.2007.06.001.

[32] J.A. Dean, Lange's handbook of chemistry. 15th ed. McGrawl-Hill Inc, 1999.

[33] A.P. Kirchheim, Aluminatos tricálcico cúbico e ortorrômbico: análise da hidratação in situ e produtos formados. Ph.D. Thesis (2008).

[34] F.P. Glasser, The stability of ettringite In: International RILEM TC 186-ISA Workshop on internal sulfate attack and delayed ettringite formation. Villars, Switzerland, September/2002. 
[35] L. Pelletier-Chaignat, F. Winnefeld, B. Lothenbach, C.J. Müller, Beneficial use of limestone filler with sulphoaluminate cement, Constr. Build. Mater. 26 (2012) 619-627. doi:10.1016/j.conbuildmat.2011.06.065.

[36] B. Lothenbach, P. Durdzinski, K.D.E. Weerdt, Thermogravimetric analysis, in: A Pract. Guid. to Microstruct. Anal. Cem. Mater., CRC Press, 2015: pp. 177-212. doi:doi:10.1201/b19074-6.

[37] G. Li, P. Le Bescop, The U phase formation in cement-based systems containing high amounts of $\mathrm{Na}_{2} \mathrm{SO}_{4}$, Cem. Concr. Res. 26 (1996) 27-33.

[38] C. Maltese, C. Pistolesi, A. Bravo, F. Cella, T. Cerulli, D. Salvioni, et al., Effects of alkali metal hydroxides on alkali-free accelerators, Adv. Cem. Res. 23 (2011) 277288. doi:10.1680/adcr.2011.23.6.277.

[39] M.J. Sánchez-Herrero, A. Fernández-Jiménez, A. Palomo, $\mathrm{C}_{4} \mathrm{~A}_{3} \mathrm{~S}$ hydration in different alkaline media, Cem. Concr. Res. 46 (2013) 41-49.

[40] C.I. Goodier, Wet-process sprayed mortar and concrete for repair. Ph.D. Thesis (2000). 